Klein et al.

Published in final edited form as:

Nat Rev Immunol. 2019 Jan;19(1):7-18. doi: 10.1038/s41577-018-0083-6.

\title{
Central $\mathrm{CD}^{+} \mathrm{T}$ cell tolerance: deletion versus regulatory $\mathrm{T}$ cell differentiation
}

Ludger Klein ${ }^{1^{*}}$, Ellen A. Robey ${ }^{2}$ and Chyi-Song Hsieh ${ }^{3}$

${ }^{1}$ Institute for Immunology, Biomedical Center, Ludwig Maximilians Universität, Planegg-Martinsried, Germany.

${ }^{2}$ Division of Immunology and Pathogenesis, Department of Molecular and Cell Biology, University of California Berkeley, Berkeley, CA, USA.

${ }^{3}$ Department of Internal Medicine, Division of Rheumatology, Washington University School of Medicine, St. Louis, MO, USA.

*e-mail: ludger.klein@med.Imu.de

\begin{abstract}
The diversion of $\mathrm{MHC}$ class II-restricted thymocytes into the regulatory $\mathrm{T}\left(\mathrm{T}_{\text {reg }}\right)$ cell lineage is driven by intrathymic encounter of agonist self-antigens, in a similar manner to the clonal deletion of thymocytes. Somewhat paradoxically, it thus seems that the expression of an autoreactive $T$ cell receptor is a shared characteristic of $T$ cells that are subject to clonal deletion and $T$ cells that are diverted into the $T_{\text {reg }}$ cell lineage. Here, we discuss how thymocyte-intrinsic and thymocyte-extrinsic determinants may specify the choice between these two fundamentally different $T$ cell fates.
\end{abstract}

This Review is dedicated to the memories of Bruno Kyewski and Harald von Boehmer, who both made seminal contributions to our understanding of central tolerance and who passed away in 2018. 
Klein et al.

\section{Introduction}

A series of landmark studies in the late 1980s confirmed the longstanding hypothesis that tolerance to 'self' involves the clonal deletion in the thymus of $T$ cells with potentially dangerous, self-reactive $T$ cell receptors $(T C R s)^{1,2}$. Around the same time, the transplantation of thymic epithelium was reported to confer a mode of tolerance to donor-type tissues that could not be explained by recessive tolerance mechanisms such as clonal deletion, as it was transferrable to naive animals through the injection of lymphocytes and hence was referred to as dominant tolerance ${ }^{3-5}$. Several independent lines of investigation subsequently illustrated the importance of dominant tolerance by showing that the elimination of particular subsets of $\mathrm{CD} 4^{+} \mathrm{T}$ cells, all later shown to be the equivalent of forkhead box protein P3 (FOXP3) ${ }^{+}$regulatory $T\left(T_{\text {reg }}\right)$ cells, unleashed a latent autoimmune potential in the normal T cell repertoire ${ }^{6-8}$. It is believed that approximately $80 \%$ of the $T_{\text {reg }}$ cell repertoire originates from the thymus (known as thymus-derived $\mathrm{T}_{\text {reg }}$ cells) ${ }^{9,10}$, where FOXP3 ${ }^{+} \mathrm{T}_{\text {reg }}$ cell differentiation can be 'instructed' by encounter of agonist self-antigen ${ }^{11,12}$. Thus, the recognition of self during thymocyte differentiation can not only generate 'holes' in the T cell repertoire by clonal deletion, but also specify the diversion of cells into a self-reactive $T$ cell lineage that lacks autoimmune potential and instead confers tolerance through immune regulation.

The conceptually most simple models to explain these markedly different outcomes of self-antigen recognition in the thymus are based on the affinity and/or avidity of the underlying TCR-peptide-MHC (TCR-pMHC) interactions (FIG. 1).

\section{Recessive tolerance}

Any mode of tolerance that depends on clonal deletion or anergy induction. The term recessive refers to the fact that in order to be effective, essentially all self-reactive $T$ cells need to be physically eliminated or functionally inactivated.

\section{Dominant tolerance}

Any mode of tolerance that depends on the suppressive action of regulatory cells and can therefore be transferred from tolerant to naive individuals.

\section{Thymus-derived $T_{\text {reg }}$ cells}

These cells enter the $T_{\text {reg }}$ cell lineage as a consequence of cell fate specification during $T$ cell maturation in the thymus. By contrast, peripherally derived $T_{\text {reg }}$ cells arise through conversion of conventional FOXP3- ${ }^{-} D 4^{+}$cells in secondary lymphoid organs. 
Klein et al.

However, although there is little doubt that TCR signals crucially impact the cell fate decisions of thymocytes, reductionist 'signal strength' models do not explain phenomena such as the intraclonal competition between $\mathrm{T}_{\text {reg }}$ cell precursors ${ }^{13,14}$, the overlapping TCR repertoires of conventional $T$ cells and $T_{\text {reg }}$ cells ${ }^{15,16}$ or the concomitant clonal deletion that occurs in essentially all TCR transgenic systems where neo-antigen expression drives efficient $T_{\text {reg }}$ cell diversion ${ }^{17-20}$. All of these observations argue against the existence of sharply demarcated affinity and/or avidity thresholds that separate clonal deletion and $T_{\text {reg }}$ cell diversion. In this Review, we discuss how the cell fate choice between clonal deletion and diversion into the $T_{\text {reg }}$ cell lineage may be influenced by distinct modalities of intrathymic self-antigen expression and presentation, spatio-temporal aspects of thymocyte differentiation and 'contextual' input that accompanies the agonist TCR signal.

\section{Topology of self-antigen expression}

Self-antigens can be broadly categorized into those with a ubiquitous expression pattern and those with an expression pattern that is confined to one or a few anatomical sites, known as tissue-restricted antigens (TRAs). It is now widely recognized that TRAs are also likely to be 'visible' to the nascent $T$ cell repertoire, owing to the phenomenon of promiscuous gene expression in medullary thymic epithelial cells (mTECs) (BOX 1). Although it is undisputed that promiscuous gene expression extends the scope of central tolerance to a much broader spectrum of self-antigens than previously appreciated, insights are only beginning to emerge regarding whether and how distinct patterns of antigen expression may specify the mechanism of central tolerance induction for $\mathrm{CD}^{+} \mathrm{T}$ cells and how this affects the composition of the polyclonal TCR repertoire.

\section{Tissue-restricted antigens}

(TRAs). Self-antigens that are expressed by only one or a few peripheral tissues. The term TRA is an operational definition based on available expression catalogues, according to which TRAs are expressed in less than 5 tissues of 60 tested.

\section{Central tolerance}

Any mechanism of tolerance that shapes the $T$ cell receptor composition and functionality of the $T$ cell repertoire during selection in the thymus. 
Klein et al.

Two recent studies used $\mathrm{MHC}$ class II tetramer technology to trace the fate of small cohorts of polyclonal $\mathrm{CD}^{+} \mathrm{T}$ cells when their cognate antigens were expressed as neo-self antigens under the control of various promoters to achieve either a ubiquitous or a TRA-like expression pattern ${ }^{21,22}$. Ubiquitous antigen expression led to a largescale reduction in the number of antigen-specific $\mathrm{CD} 4^{+} \mathrm{T}$ cells, which was evident already in the nascent $\mathrm{CD}^{+}$single positive (SP) compartment, indicating efficient clonal deletion. By contrast, under circumstances of TRA-like antigen expression, antigen-specific $\mathrm{CD} 4^{+} \mathrm{T}$ cells were only mildly or not at all affected in terms of their absolute numbers yet harboured a substantial fraction of $\mathrm{FOXP}^{+} \mathrm{T}_{\text {reg }}$ cells. On this basis, it was suggested that the mechanism of $\mathrm{CD} 4^{+} \mathrm{T}$ cell tolerance is determined by the antigen expression pattern, whereby ubiquitous expression favours deletional tolerance, whereas TRA-like modalities of antigen expression promote diversion into the $T_{\text {reg }}$ cell lineage.

Studies in mice lacking the autoimmune regulator protein (AIRE) (Aire ${ }^{-/}$mice), which have decreased expression of many TRAs, are consistent with a role of TRAs in Treg cell generation. For example, large-scale TCR sequencing revealed 'holes' in the $T_{\text {reg }}$ cell repertoire of Aire ${ }^{-/-}$mice, and an intact Aire gene was crucial for the capacity of several TCRs of unknown specificity from naturally occurring $T_{\text {reg }}$ cells to promote intrathymic clonal diversion into the $T_{\text {reg }}$ cell lineage ${ }^{23,24}$. In further support of TRAs shaping the composition of the $T_{\text {reg }}$ cell repertoire, adoptively transferred neonatal $T_{\text {reg }}$ cells from Aire $^{+/+}$mice, but not Aire $^{-/-}$mice, prevented the autoimmune manifestations seen in AIRE-deficient mice ${ }^{25}$.

\section{MHC class II tetramer}

A staining reagent used to detect antigen-specific $C D 4^{+} T$ cells. It consists of four recombinantly expressed biotinylated $\mathrm{MHC}$ class II molecules (each carrying a covalently attached peptide epitope of interest) that are tetramerized via a fluorochrome-labelled streptavidin core.

\section{Autoimmune regulator protein}

(AIRE). AIRE was discovered through genetic mutation in patients with the monogenically inherited disease autoimmune polyendocrine syndrome 1 (APS1). It is a transcriptional regulator that controls the expression of TRAs in mTECs, but may also have similar or distinct functions in cells other than mTECs. 
Klein et al.

Although these findings establish that intrathymic antigen expression in a TRA-like manner can specify $T_{\text {reg }}$ cell diversion, they do not rule out that promiscuous gene expression also contributes to clonal deletion. Indeed, observations in several TCRtransgenic systems have linked promiscuous gene expression and AIRE expression to deletional $\mathrm{CD}^{+} \mathrm{T}$ cell tolerance ${ }^{26-29}$. Similarly, tetramer-based studies showed that polyclonal $\mathrm{CD}^{+} \mathrm{T}$ cells specific for an eye-restricted TRA were deleted in an AIREdependent manner ${ }^{30}$. Expression of green fluorescent protein (GFP) as a TRA-like neo-self antigen under the control of the insulin promoter resulted in a significant decrease in the number of polyclonal GFP-specific $\mathrm{CD} 4^{+} \mathrm{T}$ cells coincident with the emergence of $\mathrm{FOXP3}^{+}$cells among the remainder of GFP-specific cells, which suggests that clonal deletion and diversion into the $T_{\text {reg }}$ cell lineage occurred in paralle $\left.\right|^{22}$. Of note, the intensity of tetramer staining on these $T_{\text {reg }}$ cells was lower as compared with their naive counterparts in the absence of GFP, which suggests that $T$ cell clones expressing TCRs with high affinity for GFP may have been deleted.

In sum, the propensity of ubiquitous versus TRA-like modes of antigen expression to favour clonal deletion versus $T_{\text {reg }}$ cell development, respectively, may relate to quantitative differences in the amount of self-antigen, which is in keeping with an avidity-based model. However, as we discuss in the following sections, we also need to consider the following factors: the different spatial distribution of antigen expression and consequently the developmental stage at which these antigens are first seen by a thymocyte; the likelihood and frequency of serial antigen encounters; the antigenpresenting cell (APC) type(s) that display the respective self-antigen; and, related to this, the co-signals such as cytokines or co-stimulatory molecules that accompany the TCR signal.

\section{T cell developmental stage}

Intrathymic $\mathrm{T}$ cell development is characterized by a highly ordered migration of thymocytes between distinct areas of the thymus ${ }^{31,32}$. Ubiquitously expressed antigens are expected to be visible to developing thymocytes in the cortex as soon as these cells express a functionally rearranged TCR at the $\mathrm{CD} 4^{+} \mathrm{CD} 8^{+}$double positive (DP) stage. By contrast, owing to their confined expression in mTECs, TRAs are expected to be encountered only after $\mathrm{CD}^{+}$or $\mathrm{CD}^{+}$lineage-committed SP $\mathrm{T}$ cells have relocated to the medulla ${ }^{33}$. This raises the question of how the developmental stage at which thymocytes receive an agonist TCR signal influences the mode of tolerance. Remarkably, despite relatively low levels of TCR expression on the surface of DP thymocytes, they are exquisitely sensitive to antigen. In fact, whereas the estimated 
Klein et al.

minimum number of pMHC complexes required to activate mature peripheral T cells is believed to be in the order of 100 , as few as one or two agonist pMHC complexes seem to be sufficient to elicit clonal deletion at the DP thymocyte stage $\mathrm{e}^{34,35}$. Importantly, this implies that at the DP stage (and at least for high-affinity TCR-pMHC combinations), there is almost no possibility of a lower avidity interaction as a consequence of lower $\mathrm{pMHC}$ density that might favour $\mathrm{T}_{\text {reg }}$ cell diversion.

Indeed, although it is well established that cortical antigen encounter by DP thymocytes can result in clonal deletion ${ }^{36,37}$, its contribution to $T_{\text {reg }}$ cell differentiation remains contentious. For example, FOXP3-expressing cells are almost exclusively confined to the thymic medulla, a compartment that contains hardly any DP cells. In addition, the delayed appearance of $\mathrm{FOXP}^{+}$cells in ontogeny or in bone-marrow chimeras suggests that entry into the $T_{\text {reg }}$ cell lineage requires thymocyte maturation beyond the DP stage and/or involves medulla-associated signals ${ }^{38,39}$. Such correlations entail the caveat that the timing and intrathymic positioning of FOXP3 expression may be poor indicators of when and where the underlying TCR stimulus occurred (as the transit time through the DP compartment may be shorter than the temporal delay between a TCR signal being received and FOXP3 expression being induced), but it is clear that antigen encounter at the DP stage is not a prerequisite for $T_{\text {reg }}$ cell differentiation. Instead, diversion into the $T_{\text {reg }}$ cell lineage can efficiently be initiated at the SP stage, as shown by intrathymic transfer of antigen-naive CD4 ${ }^{+}$SP cells into an antigen-expressing thymus ${ }^{40}$. These experiments also showed that the propensity of $\mathrm{CD} 4^{+} \mathrm{SP}$ cells to enter the $\mathrm{T}_{\text {reg }}$ cell lineage inversely correlated with their progressive maturation - that is, more mature cells were less likely to become $T_{\text {reg }}$ cells (and instead underwent proliferative expansion). Although this is reminiscent of a previously recognized similar transition from deletion susceptibility to deletion resistance at the $\mathrm{CD}^{+} \mathrm{SP}$ cell stage ${ }^{41}$, it is tempting to speculate that the developmentally programmed predisposition to undergo $T_{\text {reg }}$ cell differentiation is maintained for longer during $\mathrm{CD}^{+} \mathrm{SP}$ cell maturation than is the susceptibility to undergo clonal deletion.

On the basis of these combined results, it is conceivable that thymocytes transit through cell-intrinsically regulated developmental 'windows of opportunity' in which antigen encounter is differentially interpreted (FIG. 2). Whereas susceptibility to clonal deletion is established early at the DP thymocyte stage, the capacity for $T_{\text {reg }}$ cell differentiation may only be acquired in close temporal proximity to $\mathrm{CD}^{+}$lineage commitment and the relocation of $\mathrm{CD}^{+} \mathrm{SP}$ cells to the medulla. This offers an 
Klein et al.

explanation as to why $\mathrm{CD}^{+} \mathrm{T}$ cell tolerance to ubiquitously expressed and hence earlyencountered antigens may preferentially operate through clonal deletion. By contrast, a TRA-like pattern of antigen expression in the medulla would be permissive (but not per se instructive) for $T_{\text {reg }}$ cell differentiation, because these antigens are likely to be seen only once the capacity to undergo $T_{\text {reg }}$ cell differentiation has been established. Whether antigen recognition at this late stage induces clonal deletion or $\mathrm{T}_{\text {reg }}$ cell differentiation might then be determined by asynchronous loss of the susceptibility to assume either cell fate, or by the modalities of TCR signalling in conjunction with other parameters, as discussed below.

\section{Serial antigen encounters}

The mosaic-like pattern of expression of TRAs, such that only a few cells in the medulla express a given self-antigen (BOX 1), poses obvious limitations on the likelihood that a given TRA is 'seen' at all by its cognate T cells. In addition, it is conceivable that the number of APCs that present a given antigen may directly affect the ensuing mode of $\mathrm{CD}^{+} \mathrm{T}$ cell tolerance. In this regard, it is of particular relevance that most models of thymocyte selection, particularly those based upon affinity and/or avidity, assume that cell fate decisions in the thymus are based on a single thymocyte-APC interaction. However, this may not, or at least not always, be the case.

Real-time imaging of thymocyte motility in thymic slices showed that in the absence of cognate antigen, medullary thymocytes have relatively rapid motion in a 'random walk' pattern and scan their environment for cognate $\mathrm{PMHC}$ ligands through engaging in 58 short-lived contacts with APCs per hour ${ }^{42,43}$. Administration of cognate peptide to such thymus slices resulted in the migratory arrest of specific CD8 ${ }^{+} \mathrm{SP} T$ cells within minutes, followed by their apoptotic cell death within a few hours ${ }^{44}$. Thus, clonal deletion resulting from abundantly available antigen may indeed involve a single, yet sustained, thymocyte-APC interaction. By contrast, when cognate antigen was expressed endogenously in a TRA-like expression pattern in a model of steady-state negative selection of $\mathrm{CD}^{+} \mathrm{T}$ cells, there was no evidence for the migratory arrest of $\mathrm{T}$ cells. Instead, $\mathrm{CD}^{+} \mathrm{SP}$ cells continually migrated, albeit with decreased velocity, indicating that they had experienced one or several previous antigen encounter(s $)^{42}$. Whereas these experimental systems focused on TCR-transgenic CD8 ${ }^{+} \mathrm{SP} T$ cells, a similar pattern of confined migration was observed for a fraction of polyclonal MHC class I-restricted and MHC class II-restricted medullary thymocytes ${ }^{42}$. Thus, it is possible that for $\mathrm{CD}^{+} \mathrm{SP}$ thymocytes also, particular modalities of self-antigen presentation do not deliver an immediate and persistent stop signal. In such a 'multiple 
Klein et al.

hit' scenario, a mosaic-like pattern of antigen expression is more likely to result in transient TCR triggering, whereas ubiquitously expressed and presented self-antigens would provide continual TCR stimulation.

Consistent with the idea that discontinuous TCR stimulation is favourable or even essential for $\mathrm{T}_{\text {reg }}$ cell differentiation, FOXP3 induction upon in vitro stimulation of CD4 ${ }^{+}$ SP T cells with CD3-specific antibodies was most efficient when the TCR stimulus was prematurely terminated or when, subsequent to an initial phase of TCR stimulation, phosphatidyl inositol 3-kinase ( $\mathrm{PI} 3 \mathrm{~K}$ ) or its downstream signalling modules - protein kinase B (also known as AKT1) or mechanistic target of rapamycin (mTOR) - were inhibited ${ }^{45}$. Along these lines, mathematical models have suggested a signal integration model of thymocyte selection that provides a conceptual framework to understand how the TCR stimulation history may determine the outcome of thymic selection based upon a synthesis of both sustained and transient TCR signalling levels ${ }^{46}$. This model posits that clonal deletion of thymocytes may result from a strong, isolated signalling event, whereas $\mathrm{T}_{\text {reg }}$ cell differentiation may ensue from repeated, weak TCR stimulation, and it is clear how ubiquitous and high-level expression of selfantigens versus mosaic-like and low-level expression of self-antigens may favour clonal deletion versus $\mathrm{T}_{\text {reg }}$ cell differentiation (FIG. 3).

In sum, a growing body of observations indicates that clonal deletion can result from a 'single hit' of antigen that promotes immediate arrest of the thymocyte on the APC surface, which may in turn amplify the intensity and/or duration of TCR signalling ${ }^{43,47-}$ 49. However, it remains to be seen whether, by contrast, $T_{\text {reg }}$ cell differentiation involves, or even requires, multiple antigen encounters.

\section{Thymic antigen-presenting cells}

Developing thymocytes may encounter self-antigens on various types of $\mathrm{APC}^{33}$, including classical dendritic cell (cDC) subsets ${ }^{50,51}$, plasmacytoid DCs $(p D C s)^{52}, B$ cells ${ }^{53,54}$, and cortical and medullary TECs ${ }^{55}$. It is widely accepted that all of these thymic APC subtypes can induce T cell tolerance. However, their relative contributions to shaping the polyclonal $\mathrm{T}$ cell repertoire remain poorly understood, with regards to both the spectrum of self-antigens that they display as well as whether self-antigen encounter on distinct APCs preferentially or even selectively results in clonal deletion or $\mathrm{T}_{\text {reg }}$ cell induction. 
Klein et al.

Mouse models lacking cDCs or subsets of mTECs, or with absent or aberrant MHC class II expression on subclasses of thymic APCs, have been used to address these questions (reviewed $\mathrm{in}^{12}$ ). Irrespective of whether antigen presentation by DCs or mTECs was inhibited, these models showed an increase in the number of CD4 ${ }^{+}$SP T cells, which is thought to reflect the non-redundant contribution of the respective APCs to clonal deletion of MHC class II-restricted T cells ${ }^{55-57}$. By contrast, the overall size of the polyclonal $T_{\text {reg }}$ cell compartment was not markedly affected upon interfering with the capacity of individual APC subsets to contribute to central tolerance induction for $\mathrm{CD}^{+} \mathrm{T}$ cells. However, sequencing of TCRs on $\mathrm{T}_{\text {reg }}$ cells in mice lacking DCs or with decreased MHC class II expression on mTECs clearly pointed to a non-redundant contribution of these APCs to shaping the $T_{\text {reg }}$ cell repertoire at the level of individual antigen specificities ${ }^{24}$. Thus, in both mouse models, distinct sets of TCRs were absent from the $T_{\text {reg }}$ cell repertoire and instead were present in the repertoire of conventional T cells.

In sum, there is no evidence to suggest that a single thymic APC subset is specialized and required for either clonal deletion or $T_{\text {reg }}$ cell differentiation. Nonetheless, it is becoming increasingly clear that thymic APC subtypes, owing to differences in the way that they sample and process self-antigens, differ in their peptide-MHC ligandome (reviewed $\mathrm{in}^{33}$ ) (BOX 2). Irrespective of the ensuing mode of tolerance, the presentation of partly unique arrays of self-peptides by different APC subsets is expected to translate into a non-redundant role for these subsets in central tolerance to autoantigens that are not ubiquitously available.

\section{Costimulation and soluble factors}

In addition to having partly non-overlapping peptide-MHC ligandomes, thymic APC subsets may also differ in their capacity to provide non-antigenic signals that act on developing thymocytes simultaneously or in close temporal proximity to TCR stimulation. Such extrinsic cell fate determinants may be provided in the form of costimulatory molecules or soluble factors and they represent potential determinants of deletion versus diversion into the $T_{\text {reg }}$ cell lineage.

\section{Peptide-MHC ligandome}

The repertoire of peptides that are bound by MHC molecules on a given cell type. 
Klein et al.

IL-2. Together with the TCR stimulus, IL-2 has a crucial role in promoting thymic $T_{\text {reg }}$ cell development ${ }^{58}$. The relationship between TCR and cytokine signals has been framed in terms of a two-step model, whereby strong TCR signals lead to the upregulation of expression of CD25 (also known as IL-2Ra), which confers high-affinity IL-2 binding and, in turn, promotes FOXP3 upregulation ${ }^{59,60}$. CD25 $5^{+} \mathrm{FOXP}^{-}$cells are present at a frequency of $2-3 \%$ in the steady-state $\mathrm{CD} 4^{+} \mathrm{SP}$ T cell compartment. A substantial fraction of these cells gives rise to mature $\mathrm{CD} 25^{+} \mathrm{FOXP} 3^{+} \mathrm{T}_{\text {reg }}$ cells upon in vivo transfer into an MHC class II-deficient thymus or upon in vitro culture with IL-2, which indicates that a fraction of $\mathrm{CD}^{2} 5^{+} \mathrm{FOXP}^{-} \mathrm{CD}^{+} \mathrm{SP}$ thymocytes are at an intermediate developmental stage, where TCR signals are dispensable and IL-2 is sufficient for the completion of $\mathrm{T}_{\text {reg }}$ cell differentiation ${ }^{60}$. Further support for a model in which CD25 expression precedes the induction of FOXP3 in the majority of developing $T_{\text {reg }}$ cells comes from molecular timing studies in vivo ${ }^{61}$. However, there are also indications that some thymic $T_{\text {reg }}$ cells differentiate via a pathway in which the upregulation of FOXP3 expression precedes CD25 induction ${ }^{62,63}$. Moreover, other common cytokine receptor $\gamma$-chain family cytokines ( $\gamma_{c}$ cytokines), in particular IL-15, can have a redundant role in promoting $T_{\text {reg }}$ cell development ${ }^{62,64-66}$.

Levels of IL-2 in the thymus are likely to be a limiting factor for $T_{\text {reg }}$ cell differentiation ${ }^{65,67}$, which raises questions about the cellular source(s) of IL-2. In a thymic tissue slice model that recapitulates many aspects of steady-state thymic $T_{\text {reg }}$ cell development, $1 / 2^{-/-}$DCs were significantly less efficient in their ability to induce agonist-driven $\mathrm{T}_{\text {reg }}$ cell development compared with $1 / 2^{+/+} \mathrm{DCs}$, which suggests that APCs may simultaneously provide both IL-2 and the TCR ligand required for $\mathrm{T}_{\text {reg }}$ cell differentiation ${ }^{68}$.

\section{Common cytokine receptor $\gamma$-chain family cytokines}

( $\gamma_{c}$ cytokines). The heterodimeric or heterotrimeric receptors for at least six cytokines (IL-2, IL-4, IL-7, IL-9, IL-15 and IL-21) share a common $\gamma$-chain (known as $\gamma_{c}$ or CD132). The receptors for IL-2 and IL-15 also share the $\beta$-subunit (CD122), but contain distinct $\alpha$-subunits (CD25 and CD215, respectively). Both $\alpha$-subunits confer highaffinity cytokine binding, but are not directly involved in signal transduction. 
Klein et al.

By contrast, a recent study using T cell-specific, B cell-specific or DC-specific conditional //2 knockout showed that IL-2 derived from thymocytes themselves is necessary and sufficient for thymic $T_{\text {reg }}$ cell development, in particular in the absence of IL-15 $5^{69}$. Importantly, this study also used mixed chimeras to show that in $1 / 2^{-1-}$ recipients of an equal mixture of wild-type and $\mathrm{T}$ cell-specific I/2-knockout bone marrow, IL-2-deficient and IL-2-sufficient thymocytes underwent $\mathrm{T}_{\text {reg }}$ cell differentiation with identical efficacy, which indicates that autocrine IL-2 is dispensable for $T_{\text {reg }}$ cell differentiation and that IL-2 is instead provided by neighbouring $T$ cells.

The exact identity of the bystander $T$ lineage cells that produce IL-2 to support $T_{\text {reg }}$ cell differentiation remains to be established, but $\mathrm{CD} 4^{+} \mathrm{SP}$ cells differentiating into the conventional $\mathrm{CD}^{+} \mathrm{T}$ cell lineage are obvious candidates. Intriguingly, SP thymocytes acquire the competence for IL-2 production upon TCR stimulation only gradually at a late phase of maturation ${ }^{70}$. It is therefore conceivable that the availability of IL-2 to drive the second step of $\mathrm{T}_{\text {reg }}$ cell differentiation is restricted to the immediate vicinity of a few mature, pre-emigration, conventional SP T cells that produce IL-2 upon encountering rare agonist pMHC ligands (FIG. 4a). Consistent with this idea, in situ analyses showed that IL-2 protein is confined to 'haloes' surrounding a small number of IL-2-producing cells at the corticomedullary junction ${ }^{71}$. Interestingly, a fraction of both thymic cDCs and mTECs express the high-affinity CD25 chain of the IL-2 receptor, but not the signalling chain CD122 ${ }^{69}$, which suggests that these APCs may capture T cell-derived IL-2 and restrict its free diffusion. Such local retention of IL-2 by neighbouring APCs may not only reinforce the spatial constraints in IL-2 availability, but also allow for transpresentation ${ }^{72}$ of surface-bound IL-2 to developing $\mathrm{T}_{\text {reg }}$ cells.

\section{Trans-presentation}

Cytokine trans-presentation is best established for $I L-15$, whereby signalling in a responder cell results from recognition of complexes of IL-15 with the high-affinity IL$15 R \alpha$ subunit on the surface of a 'trans-presenting' cell-type, which may itself produce IL-15. It is controversial whether the high-affinity IL-2R $\alpha$ subunit (CD25) can bind IL-2 independently of other receptor subunits and thereby elicit IL-2 signalling in trans. 
Klein et al.

The amount of IL-2 available to support thymic $T_{\text {reg }}$ cell generation is not only limited by the number of IL-2-producing cells, but also controlled by a negative-feedback loop in which mature $T_{\text {reg }}$ cells restrain the de novo differentiation of $T_{\text {reg }}$ cells (FIG. 4b). Using thymic tissue slices, it was shown that existing thymic $T_{\text {reg }}$ cells within the thymic slice environment limited cytokine availability and inhibited the development of new $T_{\text {reg }}$ cells ${ }^{68}$. In a further intriguing twist, $T_{\text {reg }}$ cells can migrate back to the thymus from the periphery and so may place additional pressure on the system by also competing for IL- $2^{73}$. Curiously, the recirculation of peripheral $T_{\text {reg }}$ cells requires AIRE, which seems to reflect a role of AIRE in chemokine production by mTECs rather than in promoting TRA expression ${ }^{74}$. It remains to be established whether recirculation of $T_{\text {reg }}$ cells to the thymus is developmentally controlled, involves environmental triggers and/or selectively applies only to certain antigen specificities.

Competition for IL-2 per se is an antigen-independent process, but it also has implications for another enigmatic aspect of thymic $T_{\text {reg }}$ cell differentiation - namely, the intraclonal competition between $T_{\text {reg }}$ cell precursors of shared TCR specificity. Models in which the fate of a thymocyte is solely specified by its TCR predict that transgenic expression of a $T_{\text {reg }}$ cell-derived TCR would lead to enhanced $T_{\text {reg }}$ cell development. However, initial analyses of transgenic mice with TCRs cloned from naturally occurring $T_{\text {reg }}$ cells of unknown specificity showed that such monoclonal systems have only very small numbers of $\mathrm{FOXP3}^{+}$cells ${ }^{13,14}$. Efficient $\mathrm{T}_{\text {reg }}$ cell development was restored upon reducing the frequency of cells bearing the respective $T_{\text {reg }}$ cell-derived $\mathrm{TCR}^{13,14}$, which indicates that $\mathrm{T}_{\text {reg }}$ cell differentiation involves a limiting niche that is saturated at very low clonal frequencies. Competition for antigen is likely to be a rate-limiting determinant that restrains $T_{\text {reg }}$ cell differentiation at step one. This is supported by the observation that a gradual reduction of the frequencies of $T$ cell precursors resulted in a proportional increase in the level of TCR stimulation in developing $T_{\text {reg }}$ cells ${ }^{75}$. The mosaic-like expression pattern of many self-antigens in the thymus suggests that the thymus contains plenty of different niches tailored to promote the development of $T_{\text {reg }}$ cells with distinct self-antigen specificities. Considering the evidence for linked display of agonist pMHC complexes and trans-presented IL-2 by the same APC, it is conceivable that within these niches, $\mathrm{T}_{\text {reg }}$ cell precursors may compete for access to IL-2 as well as antigen. It is tempting to speculate that mature $T_{\text {reg }}$ cells may preferentially deplete sources of IL-2 associated with the same APC that selected them originally. This would primarily limit the development of $T_{\text {reg }}$ cells with related specificities, which potentially explains why low-frequency $T_{\text {reg }}$ cell precursors develop more efficiently than high-frequency $T_{\text {reg }}$ cell precursors (FIG. 4c). 
Klein et al.

How do these findings relate to clonal deletion? Whereas competition for a developmental niche that is defined by the availability of IL-2 may influence whether or not an antigen-primed $\mathrm{CD}^{2} 5^{+} \mathrm{FOXP3^{- }}$ thymocyte precursor gives rise to a mature $\mathrm{CD}^{2} 5^{+} \mathrm{FOXP3}^{+} \mathrm{T}_{\text {reg }}$ cell, the fate of those CD25+FOXP3- thymocytes that lose the competition for IL-2 remains to be established; it may depend on the developmental stage at which they encounter antigen, the type of APC and the affinity of the TCR. On the one hand, it is possible that IL-2-deprived autoreactive thymocytes may revert to a conventional $\mathrm{CD}^{+} \mathrm{T}$ cell fate and leave the thymus as 'escapees' from central tolerance induction. On the other hand, given the dual function of IL-2 as a factor for both differentiation and survival, it seems more likely that these cells die. Consistent with that idea, TCR-transgenic presumptive $T_{\text {reg }}$ cells that were incapable of signalling via CD25 were lost from the $T$ cell repertoire ${ }^{76}$, which suggests that for cells that are poised to enter the $\mathrm{T}_{\text {reg }}$ cell lineage, IL-2 is indeed a crucial determinant of life or death. Surprisingly little is known with regards to the possibility that classical clonal deletion may likewise involve intermediates responsive to $\gamma_{c}$ cytokines, but it is noteworthy that IL-7 can negate negative selection in particular models of clonal deletion ${ }^{77,78}$.

CD28. $C d 28^{-/-}$or $C d 80^{-1-} \mathrm{Cd} d 6^{-/-}$mice fail to generate a $\mathrm{T}_{\text {reg }}$ cell pool of normal size ${ }^{79}$. The small number of mature FOXP3 ${ }^{+} \mathrm{T}_{\text {reg }}$ cells in the thymus of $\mathrm{Cd} 28^{-/-}$mice is reminiscent of the phenotype of $1 / 2^{-1-}$ mice. However, although costimulation has been implicated in cytokine production, the $\mathrm{T}_{\text {reg }}$ cell deficiency in $\mathrm{Cd}_{28^{--}}$or $\mathrm{Cd} 8 \mathrm{O}^{-{ }_{-}} \mathrm{Cd} 86^{-/-}$ mice is not caused by deprivation of exogenous cytokines, but primarily reflects a $T$ cell-intrinsic function of the CD28-B7 signalling axis. For example, the failure of $C d 28^{-}$ ${ }^{1-}$ thymocytes to efficiently enter the $T_{\text {reg }}$ cell lineage is not rescued by the presence of bystander $\mathrm{Cd} 28^{+/+}$cells $^{80}$.

\section{CD28-B7 signalling axis}

CD28 is the prototypical costimulatory receptor expressed on the surface of $T$ cells. It can bind to CD80 (also known as B7.1) or CD86 (also known as B7.2) on the surface of antigen presenting cells. 
Klein et al.

Costimulation through CD28 is believed to function simultaneously to the TCR signal at an early stage of $\mathrm{T}_{\text {reg }}$ cell differentiation ${ }^{40,81,82}$, and one possibility is that its role is to increase the aggregate magnitude of the underlying agonist stimulus. In the context of models of $T_{\text {reg }}$ cell differentiation versus clonal deletion centred on signal strength, one may therefore hypothesize that for cells that engage in TCR-pMHC interactions of relatively low affinity or avidity, costimulation may favour $\mathrm{T}_{\text {reg }}$ cell generation over the differentiation of conventional T cells. By contrast, for TCR-pMHC interactions of relatively high affinity and/or avidity, costimulation may tip the balance between $T_{\text {reg }}$ cell differentiation and clonal deletion in favour of the latter. According to such a scenario, the smaller $\mathrm{T}_{\text {reg }}$ cell compartment of CD28-deficient mice would be expected to contain a substantially altered TCR repertoire, on the one hand depleted of cells that have escaped into the conventional $\mathrm{T}$ cell repertoire, and on the other hand harbouring TCR clones that otherwise would have undergone deletion. However, the TCR composition of the residual $\mathrm{T}_{\text {reg }}$ cell pool of $\mathrm{Cd}_{2} \mathrm{8}^{-{ }^{-}}$mice is surprisingly similar to that of wild-type mice, which suggests that CD28 does not function primarily to amplify the TCR signal strength, but to provide a qualitatively distinct signal that somehow supports the formation of a $T_{\text {reg }}$ cell compartment of normal size ${ }^{81}$. The possibility that CD28 drives the proliferative expansion of a small precursor pool of $\mathrm{T}_{\text {reg }}$ cells has been excluded $^{83}$, so it seems that CD28 functions in thymic $T_{\text {reg }}$ cell generation through a true lineage-specifying function and/or through a pro-survival function. In keeping with the latter function, and in further evidence against a role for costimulation in signal amplification, CD28 deficiency in a TCR-transgenic model of agonist-driven $T_{\text {reg }}$ cell differentiation resulted in the physical loss of presumptive $T_{\text {reg }}$ cells rather than their escape as conventional FOXP3- $\mathrm{T}^{-}$cells $^{83}$. These findings are consistent with CD28 signalling preventing the death of TCR-activated $\mathrm{T}_{\text {reg }}$ cell precursors. They suggest that whether or not CD28-mediated costimulation accompanies the underlying agonistic TCR signal can be a binary switch that specifies diversion into the $T_{\text {reg }}$ cell lineage or clonal deletion, respectively. Intriguingly, observations in other cellular contexts indicate that $C D 28$ can negatively regulate the expression of the pro-apoptotic protein BCL-2-interacting mediator of cell death (BIM; also known as BCL2L11) ${ }^{84}$, which is an essential mediator of classical clonal deletion ${ }^{85}$. However, BIM deficiency does not rescue the thymic $\mathrm{T}_{\text {reg }}$ cell defect in $\mathrm{Cd} 28^{-1-}$ mice ${ }^{86}$, which indicates that $\mathrm{CD} 28$ signalling in $\mathrm{T}_{\text {reg }}$ cell precursors either suppresses other death pathways or, in addition to suppressing BIM, concomitantly has a lineage-specifying function.

The role of CD28-mediated costimulation in classical clonal deletion has been controversial. In vitro experiments showed that CD28 signalling can increase the death 
Klein et al.

of TCR-stimulated thymocytes ${ }^{77,87}$. By contrast, numerous in vivo studies, involving either superantigen-reactive T cells or TCR-transgenic systems of negative selection, have failed to support a crucial requirement for $\mathrm{CD} 28$ in this process ${ }^{88-92}$. A more recent investigation revisited the interpretation that costimulation via CD28 is dispensable for deletional tolerance in vivo and provided an unexpected new twist. In this study, superantigen-reactive $T$ cells were absent from the mature thymocyte compartment irrespective of whether or not costimulation was available, but in the absence of CD28 this was not a consequence of their clonal deletion, but resulted from their re-direction into a $\mathrm{CD}^{-}{ }^{-} \mathrm{CD} 8^{-} \mathrm{TCR} \alpha \beta^{+}$compartment that may be the precursors of $\mathrm{CD} 8 \mathrm{aq}^{+}$ intraepithelial lymphocytes ${ }^{93}$. Thus, in the case of superantigen-mediated clonal deletion of thymocytes, CD28 seems to relay a signal that favours cell death over another agonist-driven cell fate.

Taking the results together, it seems that CD28-mediated costimulation is crucially required for both clonal deletion, at least as far as superantigen-mediated $T$ cell death is concerned, and the efficient formation of a $\mathrm{T}_{\text {reg }}$ cell compartment of normal size. Somewhat paradoxically, during $T_{\text {reg }}$ cell differentiation, CD28 seems to counteract cell death, whereas in the context of clonal deletion, it seems to promote cell death. This is reminiscent of earlier observations in T cell hybridomas that showed, depending on the signalling context, that CD28-mediated costimulation can induce either proapoptotic or anti-apoptotic genes ${ }^{94}$, and it will be interesting to dissect whether distinct molecular effectors downstream of CD28 operate in $T_{\text {reg }}$ cell differentiation versus clonal deletion.

\section{CD8 $\alpha \alpha^{+}$intraepithelial lymphocytes}

Intraepithelial lymphocytes are enriched in $\alpha \beta T$ cells that express CD8 $\alpha \alpha$ homodimers. These cells are thought to have a crucial function in immune regulation at mucosal interfaces, in particular in the intestine. There is evidence that CD8 $\alpha \alpha^{+}$ intraepithelial lymphocytes emerge from agonist selection in the thymus, but their exact developmental origin remains poorly understood. 
Klein et al.

Transforming growth factor- $\beta$. Mice lacking transforming growth factor- $\beta 1$ (TGF $\beta 1$ ) or with T cell-specific deletion of TGF $\beta$ receptors develop a fatal inflammatory disorder, which highlights the crucial role of TGF $\beta$ in T cell tolerance ${ }^{95}$. Owing to the pleiotropic functions of TGF $\beta$ in the immune system, it has been challenging to conclusively dissect the role of TGF $\beta$ during thymocyte differentiation and central tolerance induction. Thus, although it is widely accepted that TGF $\beta$ supports the in vitro conversion of naive T cells into induced FOXP3 ${ }^{+} \mathrm{T}_{\text {reg }}$ cells ${ }^{96}$ and is crucial for the in vivo conversion of naive $T$ cells into peripherally derived $T_{\text {reg }}$ cells in physiological as well as therapeutic settings ${ }^{97,98}$, an analogous role for TGF $\beta$ in thymic $T_{\text {reg cell }}$ differentiation has remained contentious. Initial analyses of TGF $\beta$-deficient mice showed that these animals have more, rather than fewer, thymic $T_{\text {reg }}$ cells when analysed at around two weeks of age ${ }^{99,100}$. However, it was later found that mice lacking the TGF $\beta$ receptor on T cells are essentially devoid of thymic $T_{\text {reg }}$ cells when analysed at an earlier time point, and that the apparently normal numbers of thymic $\mathrm{T}_{\text {reg }}$ cells at a later stage were secondary to systemic inflammation and increased levels of IL-2, which, in turn, expand what would otherwise be a very small $\mathrm{T}_{\text {reg }}$ cell population ${ }^{101}$. These data clearly show that TGF $\beta$ is required for the formation of a thymic $T_{\text {reg }}$ cell pool of normal size; however, different underlying mechanisms have been proposed.

On the one hand, it has been suggested that the function of TGF $\beta$ in the thymus is as a survival factor. Apoptosis was massively increased among $\mathrm{FOXP3}^{+}$thymocytes lacking the TGF $\beta$ receptor ${ }^{86}$. Of note, cell death in the context of classical clonal deletion mediated by CD3-specific antibody or endogenously expressed neo-antigen was also increased in the absence of TGF $\beta$ signalling, which indicates that the antiapoptotic function of TGF $\beta$ is not restricted to cells that have entered the $T_{\text {reg }}$ cell lineage, but applies more generally to all thymocytes that receive an agonist TCR stimulus $^{86,102}$. Ablation of the pro-apoptotic molecule BIM restored the thymic $T_{\text {reg }}$ cell pool to normal size in the absence of TGF $\beta$ signalling, which suggests that TGF $\beta$ is required to inhibit BIM-dependent apoptosis during thymic $T_{\text {reg }}$ cell differentiation, but is not essential for the induction of FOXP3 expression. In line with this, a conserved cis-element in the Foxp3 gene containing a TGF $\beta$ response element is crucial for the induction of peripherally derived $T_{\text {reg }}$ cells in gut-associated lymphoid tissues but is dispensable for thymic $T_{\text {reg }}$ cell differentiation ${ }^{98,103}$. 
Klein et al.

On the other hand, some findings support the idea that TGF $\beta$ not only keeps $T_{\text {reg }}$ cells alive but also specifies entry into the $T_{\text {reg }}$ cell lineage. For example, the thymic $T_{\text {reg }}$ cell compartment is not decreased in size when the TGF $\beta$ receptor is inactivated late in thymic $T_{\text {reg }}$ cell differentiation using a Foxp3-Cre system ${ }^{104}$. This indicates that TGF $\beta$ signalling is dispensable for the survival of mature thymic $T_{\text {reg }}$ cells, although it remains possible that it exerts a crucial pro-survival function at an earlier stage of thymic $T_{\text {reg }}$ cell differentiation. Upon intrathymic injection of polyclonal $\mathrm{CD} 4^{-} \mathrm{CD} 8^{-}$thymocytes, 2 $3 \%$ of these cells give rise to $\mathrm{FOXP} 3^{+} \mathrm{CD} 4^{+} \mathrm{SP}$ cells, and this is believed to mimic steady-state $\mathrm{T}_{\text {reg }}$ cell differentiation. TGF $\beta$ receptor-deficient thymocyte precursors failed to give rise to FOXP3 ${ }^{+} \mathrm{T}_{\text {reg }}$ cells in this setting, which indicates that TGF $\beta$ signalling has a direct cell-intrinsic role in the initiation of Foxp 3 transcription ${ }^{104}$. As a note of caution, however, it is not known whether the small fraction of input cells that would normally assume a $T_{\text {reg }}$ cell fate indeed failed to initiate Foxp3 transcription or instead failed to survive in this study.

In conclusion, further study is required to unravel the exact role(s) of TGF $\beta$ during thymic selection, although it is reasonable to assume that a general pro-survival function of TGF $\beta$ for TCR-signalled thymocytes and a function as a bona fide differentiation factor for $T_{\text {reg }}$ cells are not mutually exclusive. Irrespective of its exact function, the net effect of TGF $\beta$ in the thymus seems to be to restrain clonal deletion while supporting $T_{\text {reg }}$ cell development. Consequently, TGF $\beta$ is expected to adjust the balance between these two modes of central tolerance, which raises questions regarding the source(s) of TGF $\beta$ in the thymic microenvironment and whether the availability of TGF $\beta$ is subject to temporal and spatial regulation. The total amount of active TGF $\beta$ in the thymus gradually increases over the neonatal period ${ }^{104}$, showing a strong correlation with the delayed emergence of the first $T_{\text {reg }}$ cells at around day 3 after birth ${ }^{38}$. Intriguingly, the extent of thymocyte apoptosis seems to directly control the supply of intrathymic TGF $\beta$, whereby contact with dying thymocytes promotes TGF $\beta$ production by thymic macrophages and DCs (and possibly also TECs) ${ }^{104}$; this suggests some form of cross-regulation between clonal deletion and $\mathrm{T}_{\text {reg }}$ cell differentiation ${ }^{105}$.

\section{Perspectives}

Recent data have revealed intriguing correlations between ubiquitous antigen expression in the thymus and clonal deletion of thymocytes, and between TRA-like mosaic antigen expression in the thymus and diversion of thymocytes into the $\mathrm{T}_{\text {reg }}$ cell 
Klein et al.

lineage. We have discussed how these findings may relate to thymocyte-intrinsic and thymocyte-extrinsic determinants that specify the fate of autoreactive MHC class IIrestricted thymocytes. As a consequence, the thymus-derived $\mathrm{T}_{\text {reg }}$ cell repertoire should have a strong bias towards the recognition of peripheral antigens, while being largely devoid of TCR specificities for widely expressed antigens. This remains to be tested.

None of the cell fate determinants outlined here has emerged as a single switch between clonal deletion and clonal diversion, and a coherent model that incorporates all potential parameters is lacking. The strength of the underlying TCR stimulus is likely to be a prime determinant, but it remains unclear how incremental variations in TCR signalling intensity are translated into a binary cell fate decision. For example, almost nothing is known regarding how TCR signalling events in the context of step one of the two-step model of $\mathrm{T}_{\text {reg }}$ cell differentiation may qualitatively or quantitatively differ from a TCR stimulus that results in clonal deletion. Similarly, the molecular basis of differential integration of TCR signals and non-antigenic signals (costimulation and cytokines) at subsequent stages of thymocyte development is only poorly understood, and it will be interesting to unravel how stage-specific sensitization or de-sensitization of the TCR signalling machinery and/or transcriptional or epigenetic control may poise thymocytes for particular fate decisions.

With regards to a multiple hit model of thymocyte selection, improved intravital methodologies to visualize antigen recognition events simultaneously with the ensuing cell fate choice will be necessary to dissect whether sequential and intermittent encounters with agonist ligands in vivo are a prerequisite for $T_{\text {reg }}$ cell differentiation or simply reflect the pre-emigration behaviour of $T_{\text {reg }}$ cells subsequent to and independent of the actual lineage-instructing TCR stimulus. Of note, it remains to be seen how a model of $\mathrm{T}_{\text {reg }}$ cell generation that is based upon serial, short-lived encounters with antigen can be reconciled with a limiting niche model that presumes prolonged retention of $\mathrm{T}_{\text {reg }}$ cells and competition for antigen and IL-2 in the instructing microenvironment.

Finally, a deeper understanding of the determinants of clonal deletion versus $T_{\text {reg }}$ cell diversion in the thymus is complicated by the fact that both cell fates might be achieved via pathways that are more heterogeneous than commonly assumed. On the one hand, there are hints that classical clonal deletion differs in its requirements for costimulation and/or apoptotic effector pathways depending on the developmental 
Klein et al.

stage of thymocytes ${ }^{41}$. On the other hand, $T_{\text {reg }}$ cell development may occur via different pathways that are characterized by differences in the order of expression of CD25 and FOXP3. Importantly, irrespective of whether $\mathrm{T}_{\text {reg }}$ cell differentiation proceeds via $\mathrm{CD}^{2} 5^{+} \mathrm{FOXP3}^{-}$or $\mathrm{CD}^{-} 5^{-} \mathrm{FOXP3}^{+}$intermediates, both pathways of $\mathrm{T}_{\text {reg }}$ cell differentiation seem to involve apoptosis-prone transitional stages at which cells compete for cytokines as survival factors. Thus, a substantial fraction of TCR-signalled $\mathrm{T}_{\text {reg }}$ cell intermediates may die because of cytokine deprivation, which raises the possibility that blunted $\mathrm{T}_{\text {reg }}$ cell differentiation represents a significant, if not major, pathway of clonal deletion at the $\mathrm{CD} 4^{+} \mathrm{SP}$ stage. 
Klein et al.

\section{Box 1 | Promiscuous gene expression in the thymus}

Tightly controlled expression of genetic programmes is a hallmark of tissue identity. However, in violation of this rule, medullary thymic epithelial cells (mTECs) express a large number of mRNAs encoding self-antigens whose expression is otherwise under stringent developmental, spatial and temporal control, known as tissue-restricted antigens (TRAs) ${ }^{106,107}$. The expression of more than three thousand TRA transcripts is controlled by the autoimmune regulator protein (AIRE). AIRE lacks features of classical transcription factors and instead seems to facilitate ectopic transcription indirectly through binding to inactive histone marks and promoting the subsequent recruitment of factors associated with chromatin opening, release of stalled RNA polymerase and transcript maturation ${ }^{108,109}$. AIRE is essential for T cell tolerance, as is evident from the autoimmune manifestations that occur in AIRE-deficient humans and mice.

Promiscuous gene expression of TRAs is not fully abolished in the absence of AIRE ${ }^{110}$, and recent data suggest that the transcription factor Fez family zinc finger protein 2 (FEZF2) might be a second, independent regulator of promiscuous gene expression ${ }^{111}$. In support of this, FEZF2-dependent TRA expression is not affected in AIRE-deficient mTECs, and FEZF2 deficiency in thymic epithelium elicits a spectrum of autoimmune manifestations that is partly distinct from those in AIRE-deficient mice.

At the population level, mTECs express the highest number of genes $(>85 \%$ of all protein coding transcripts) observed in any cell type ${ }^{112}$ and thereby provide a comprehensive representation of peripheral self-antigens. However, the expression of a given TRA is, in many cases, confined to only $1-3 \%$ of all mTECs ${ }^{33,107}$. For example, pioneering early studies showed that an adult mouse thymus contains a few hundred cells that express pancreas-specific TRAs ${ }^{113}$, whereas the total number of mTECs is in the order of 100,000. Recent comparisons of gene expression profiles of mTECs at the single cell level confirmed that there is a substantial degree of cell-to-cell variation in the transcriptomes of mTECs, which further substantiates the idea that promiscuous gene expression entails a stochastic component ${ }^{33,112,114,115}$.

\section{Ectopic transcription}

Expression of a tissue-specific mRNA in a cell type where the respective gene product does not have any obvious function. 
Klein et al.

\section{Box 2 | The peptide-MHC class II ligandomes of thymic antigen-presenting cells}

Thymic antigen-presenting cell (APC) subsets are expected to display partly nonoverlapping peptide- $\mathrm{MHC}$ class II ligandomes, owing to differences in their origin and the way in which they capture and process antigens (reviewed $\mathrm{in}^{33}$ ). Cortical thymic epithelial cells (cTECs) express unusual proteases whose proteolytic activity differs from the antigen processing that occurs in other APCs. These cTEC-specific proteases are not at all or only weakly expressed in other cell types and they have been implicated in the generation of unique MHC class I-bound and MHC class II-bound peptides for positive selection. Medullary TECs (mTECs), like cTECs, are inefficient in loading extracellular self-antigens onto MHC class II molecules. Instead, both cTECs and mTECs seem to preferentially use non-canonical MHC class II loading pathways for endogenous antigens ${ }^{116}$. In the case of mTECs, a peptide-MHC class II ligandome predominantly composed of endogenously derived substrates is expected to include tissue-restricted antigens (TRAs). Variability in the expression of TRAs between individual mTECs is likely to result in a corresponding degree of variability also in their peptide-MHC class II ligandomes.

Classical dendritic cells (cDCs) in the thymus segregate into at least two subsets ${ }^{50}$. Migratory $\mathrm{CD}^{-} \mathrm{SIRPa}{ }^{+} \mathrm{CDCs}$ migrate into the thymus from the circulation and their peptide-MHC class II ligandomes may contain epitopes derived from self-antigens that have been captured in the periphery ${ }^{117}$. Resident $\mathrm{CD}^{+}{ }^{+} \mathrm{SIRPa} \alpha^{-} \mathrm{CDCs}$ arise through intrathymic differentiation. Similar to their migratory counterparts, they efficiently sample extracellular sources of self-antigen. Although both types of thymic cDC may thereby capture and present mTEC-derived antigens, resident $\mathrm{cDCs}$ may be particularly efficient in doing so ${ }^{118}$, as supported by $T$ cell receptor repertoire studies ${ }^{24}$. Approximately one third of thymic DCs are plasmacytoid DCs (pDCs); pDCs are of extrathymic origin and are capable of inducing central tolerance to self-antigens that have been captured at peripheral sites $^{52}$.

Thymic B cells may originate from intrathymic B lymphopoiesis, but they can also be of extrathymic origin. Unlike mainstream peripheral B cells, thymic B cells have prominent APC features, such as high levels of expression of MHC class II molecules and CD80. Curiously, they also express AIRE, but the functional significance of this finding remains to be established ${ }^{53,54}$. It has been speculated that the self-peptideMHC class II ligandome of thymic B cells may mirror that of germinal centre B cells and/or contain self-antigens that have been captured via autoractive B cell receptors. 
Klein et al.

\section{Figure Legends}

Figure $1 \mid$ Signal strength models of clonal deletion versus $T_{\text {reg }}$ cell differentiation. The term affinity describes the strength of a single interaction between a $\mathrm{T}$ cell receptor (TCR) and its peptide-MHC (pMHC) ligand, whereas the term avidity is proportional to the multiplicity of such interactions. (a) According to an affinity-based model of thymocyte development, at a given fixed density of cognate pMHC in the thymus, T cells bearing the highest affinity TCRs are removed from the repertoire by clonal deletion, whereas T cells bearing TCRs of intermediate affinity are diverted into the regulatory $T\left(T_{\text {reg }}\right)$ cell repertoire. $T$ cells bearing TCRs of low affinity 'escape' into the periphery as conventional $\mathrm{T}$ cells. Although this prediction has so far not been addressed in a polyclonal setting, the affinity-based model is supported by a study showing that at a fixed level of neo-self-antigen expression, the efficiency of $T_{\text {reg }}$ cell selection was directly correlated with the reactivity of different TCRs ${ }^{119}$. (b) An aviditybased model posits that in addition to the TCR affinity, the density of the pMHC ligand is also crucial. At a given fixed TCR affinity, increasing or decreasing the density of antigen presented on thymic antigen-presenting cells will bias the cell fate towards either clonal deletion or $T_{\text {reg }}$ cell differentiation, respectively. Several experimental observations are consistent with this model. First, TCR-transgenic models have shown a clear correlation between antigen expression levels and the ensuing cell fate ${ }^{20,120}$. Second, the titrated administration of agonist peptide to TCR-transgenic fetal thymic organ cultures or through intravenous injection into adult mice revealed a positive correlation between agonist concentration and the number of $\mathrm{T}_{\text {reg }}$ cells; above a certain threshold, further increasing the peptide dose resulted in thymocyte deletion ${ }^{121,122}$. Third, at fixed levels of antigen expression, attenuating cognate antigen presentation through the knockdown of MHC class II expression resulted in decreased clonal deletion and increased emergence of $\mathrm{T}_{\text {reg }}$ cells ${ }^{55}$. Finally, low-affinity or high-affinity peptide ligands for the same TCR can instruct $T_{\text {reg }}$ cell differentiation with equal efficiency provided that the density of the low-affinity ligand is correspondingly higher $^{123}$.

Figure 2 | How T cell-intrinsic developmental 'windows of opportunity' may influence the mode of $\mathrm{CD4}^{+} \mathrm{T}$ cell tolerance. Immature thymocytes have an inherent predisposition to undergo apoptotic cell death upon agonist antigen encounter, whereas fully mature $T$ cells respond to antigenic stimulation by proliferation and the acquisition of effector function. The transition from a deletion-sensitive to a deletionresistant state seems to coincide with progressive thymocyte maturation at the single 
Klein et al.

positive (SP) stage. Thus, cortical double positive (DP) thymocytes and medullary SP thymocytes with an immature ( $\mathrm{HSA}^{\text {hi }}$ ) phenotype are susceptible to clonal deletion, whereas more mature ( $\mathrm{HSA}^{\text {low }}$ ) cells are not ${ }^{41}$. It remains poorly understood when and where during thymocyte development the capacity to undergo regulatory $T\left(T_{\text {reg }}\right)$ cell differentiation is established, but it is conceivable that concomitant with gradually losing their susceptibility to deletion, medullary CD4 ${ }^{+}$SP thymocytes enter a transient phase of inclination towards the $T_{\text {reg }}$ cell lineage. Consistent with this, efficient $T_{\text {reg }}$ cell differentiation was observed when the developmental window for clonal deletion was experimentally bypassed by intrathymic injection of semi-mature, antigen-naive $\mathrm{T}$ cell receptor (TCR)-transgenic $\mathrm{CD}^{+} \mathrm{SP}$ cells into a microenvironment in which clonal deletion was the prevalent tolerance mechanism in the steady state ${ }^{40}$.

Figure 3 | Model for thymocyte integration of TCR signalling strength and number of antigen encounters. (a) Antigens that are expressed ubiquitously and presented at high levels - high levels of peptide-MHC (pMHC) shown in dark red on thymic antigen-presenting cells (APCs) may favour clonal deletion of specific thymocytes through the induction of an isolated strong T cell receptor (TCR) signal. Immediate arrest of strongly TCR-signalled thymocytes on the APC surface may prolong the duration of TCR signalling and thereby establish a feed-forward loop that amplifies the aggregate signal input. (b) A mosaic pattern of self-antigen expression and presentation at comparably low levels (as indicated by the lighter red shading of thymic APCs) - as is typical for tissue-restricted antigens - may allow for serial, yet temporally separated, sub-threshold antigen encounters during continual migration of thymocytes through the thymic medulla. This mode of antigen recognition was suggested to favour regulatory $\mathrm{T}\left(\mathrm{T}_{\text {reg }}\right)$ cell differentiation ${ }^{46}$.

Figure 4 | Model of limited developmental niches for antigen-specific $T_{\text {reg }}$ cells. (a) A thymic niche for regulatory $T\left(T_{\text {reg }}\right)$ cell development is defined by a rare antigenpresenting cell (APC) that presents a particular, possibly tissue-restricted antigen (TRA)-derived, agonist self-peptide and by an IL-2 source in the immediate vicinity. IL2 produced by a relatively mature, conventional self-reactive $C D 4^{+}$single positive (SP) thymocyte (possibly an escapee from clonal deletion) remains associated with the niche as a result of limited diffusion of IL-2 and/or the capture and trans-presentation of IL-2 by the IL-2 receptor $\alpha$-subunit (IL-2Ra) expressed on the APC. The $T_{\text {reg }}$ cell progenitor receives both a strong $T$ cell receptor (TCR) signal and IL-2, allowing its development into a mature forkhead box protein P3 (FOXP3) ${ }^{+} \mathrm{T}_{\text {reg }}$ cell. (b) TCR- 
Klein et al.

specificity-independent feedback inhibition of $T_{\text {reg }}$ cell differentiation. Mature $T_{\text {reg }}$ cells in the thymus, including both recently differentiated cells and re-immigrants from the peripheral circulation, require and consume IL-2 as a survival factor and thereby deplete IL-2 from the thymic niche. IL-2 depletion limits the ability of newly TCR-primed (step one) thymocyte progenitors to undergo step two of $T_{\text {reg }}$ cell differentiation. IL-2deprived progenitors may either revert to the conventional T cell lineage or, perhaps more likely, undergo deletion. (c) Intraclonal competition for antigen and IL-2 between $T_{\text {reg }}$ cell progenitors of identical specificity. The first thymocyte progenitor (orange) that enters the thymic niche undergoes complete maturation into a $T_{\text {reg }}$ cell (left panel). Once a mature $\mathrm{T}_{\text {reg }}$ cell, this cell may 'sequester' cognate $\mathrm{pMHC}$ complexes and deplete local IL-2, thereby interfering with step one (middle panel) and/or step two (right panel), respectively, of $\mathrm{T}_{\text {reg }}$ cell differentiation of subsequently incoming progenitors (blue and green) of the same specificity. The alternative fate of outcompeted precursors could be escape from central tolerance induction to become conventional T cells (more likely in the case of competition for antigen) or deletion through apoptosis (more likely in the case of competition for IL-2). Both types of intraclonal competition would require, or at least be enhanced by, prolonged retention of recently matured $T_{\text {reg }}$ cells in the selecting niche. 
Klein et al.

\section{Acknowledgements}

L.K. receives support from the Deutsche Forschungsgemeinschaft (CRC 1054 'Control and plasticity of cell fate decisions in the immune system') and the European Research Council (ERC-2016-ADG 742290 - TOLERANCE FOOTPRINT). E.A.R is supported by grants from the US National Institutes of Health (NIH Al064227 and Al065537). C.S.H. is supported by NIH AI079187 and Al131349.

\section{Author contributions}

The authors contributed equally to all aspects of the article.

\section{Competing interests}

The authors declare no competing interests.

\section{Publisher's note}

Springer Nature remains neutral with regard to jurisdictional claims in published maps and institutional affiliations. 


\section{References}

1 Kappler, J. W., Roehm, N. \& Marrack, P. T cell tolerance by clonal elimination in the thymus. Cell 49, 273-280 (1987).

2 Kisielow, P., Bluthmann, H., Staerz, U. D., Steinmetz, M. \& von Boehmer, H. Tolerance in T-cell-receptor transgenic mice involves deletion of nonmature CD4+8+ thymocytes. Nature 333, 742-746 (1988).

3 Modigliani, Y. et al. Lymphocytes selected in allogeneic thymic epithelium mediate dominant tolerance toward tissue grafts of the thymic epithelium haplotype. Proc. Natl. Acad. Sci. U S A 92, 7555-7559 (1995).

4 Ohki, H., Martin, C., Corbel, C., Coltey, M. \& Le Douarin, N. M. Tolerance induced by thymic epithelial grafts in birds. Science 237, 1032-1035 (1987).

5 Salaun, J. et al. Thymic epithelium tolerizes for histocompatibility antigens. Science 247, 1471-1474 (1990).

6 Fowell, D. \& Mason, D. Evidence that the T cell repertoire of normal rats contains cells with the potential to cause diabetes. Characterization of the CD4+ $\mathrm{T}$ cell subset that inhibits this autoimmune potential. J. Exp. Med. 177, 627-636 (1993).

7 Powrie, F., Leach, M. W., Mauze, S., Caddle, L. B. \& Coffman, R. L. Phenotypically distinct subsets of CD4+ T cells induce or protect from chronic intestinal inflammation in C. B-17 scid mice. Int. immunol. 5, 1461-1471 (1993). Sakaguchi, S., Sakaguchi, N., Asano, M., Itoh, M. \& Toda, M. Immunologic selftolerance maintained by activated $T$ cells expressing IL-2 receptor alpha-chains (CD25). Breakdown of a single mechanism of self-tolerance causes various autoimmune diseases. J. Immunol. 155, 1151-1164 (1995).

9 Thornton, A. M. et al. Expression of Helios, an Ikaros transcription factor family member, differentiates thymic-derived from peripherally induced Foxp3+ T regulatory cells. J. Immunol. 184, 3433-3441 (2010).

10 Weiss, J. M. et al. Neuropilin 1 is expressed on thymus-derived natural regulatory $T$ cells, but not mucosa-generated induced Foxp3+ T reg cells. J. Exp. Med. 209, 1723-1742, S1721 (2012).

11 Hsieh, C. S., Lee, H. M. \& Lio, C. W. Selection of regulatory T cells in the thymus. Nature Rev. Immunol. 12, 157-167 (2012).

12 Klein, L. \& Jovanovic, K. Regulatory T cell lineage commitment in the thymus. Semin. Immunol. 23, 401-409 (2011).

13 Bautista, J. L. et al. Intraclonal competition limits the fate determination of regulatory T cells in the thymus. Nature Immunol. 10, 610-617 (2009).

14 Leung, M. W., Shen, S. \& Lafaille, J. J. TCR-dependent differentiation of thymic Foxp3+ cells is limited to small clonal sizes. J. Exp. Med. 206, 2121-2130 (2009).

15 Hsieh, C. S., Zheng, Y., Liang, Y., Fontenot, J. D. \& Rudensky, A. Y. An intersection between the self-reactive regulatory and nonregulatory $\mathrm{T}$ cell receptor repertoires. Nature Immunol. 7, 401-410 (2006).

16 Pacholczyk, R., Ignatowicz, H., Kraj, P. \& Ignatowicz, L. Origin and T cell receptor diversity of Foxp3+CD4+CD25+ T cells. Immunity 25, 249-259 (2006).

17 Apostolou, I., Sarukhan, A., Klein, L. \& von Boehmer, H. Origin of regulatory T cells with known specificity for antigen. Nature Immunol. 3, 756-763 (2002).

18 Jordan, M. S. et al. Thymic selection of CD4+CD25+ regulatory T cells induced by an agonist self-peptide. Nature Immunol. 2, 301-306 (2001).

19 Klein, L., Khazaie, K. \& von Boehmer, H. In vivo dynamics of antigen-specific regulatory $\mathrm{T}$ cells not predicted from behavior in vitro. Proc. Natl. Acad. Sci. U $S$ A 100, 8886-8891 (2003).

20 Picca, C. C. et al. Thymocyte deletion can bias Treg formation toward lowabundance self-peptide. Eur. J. Immunol. 39, 3301-3306 (2009). 
21 Legoux, F. P. et al. CD4+ T Cell Tolerance to Tissue-Restricted Self Antigens Is Mediated by Antigen-Specific Regulatory $\mathrm{T}$ Cells Rather Than Deletion. Immunity 43, 896-908 (2015).

22 Malhotra, D. et al. Tolerance is established in polyclonal CD4(+) T cells by distinct mechanisms, according to self-peptide expression patterns. Nature Immunol. 17, 187-195 (2016).

References 21 and 22 indicate that in the polyclonal repertoire, a TRA-like pattern of antigen expression favours $T_{\text {reg }}$ cell induction over deletion, which reveals a correlation between self-antigen expression patterns and the mode of $\mathrm{CD}^{+} \mathrm{T}$ cell tolerance.

23 Malchow, S. et al. Aire Enforces Immune Tolerance by Directing Autoreactive T Cells into the Regulatory T Cell Lineage. Immunity 44, 1102-1113 (2016).

24 Perry, J. S. et al. Distinct contributions of Aire and antigen-presenting-cell subsets to the generation of self-tolerance in the thymus. Immunity 41, 414426 (2014).

25 Yang, S., Fujikado, N., Kolodin, D., Benoist, C. \& Mathis, D. Immune tolerance. Regulatory $T$ cells generated early in life play a distinct role in maintaining selftolerance. Science 348, 589-594 (2015).

26 Anderson, M. S. et al. The cellular mechanism of Aire control of T cell tolerance. Immunity 23, 227-239 (2005).

27 DeVoss, J. et al. Spontaneous autoimmunity prevented by thymic expression of a single self-antigen. J. Exp. Med. 203, 2727-2735 (2006).

28 Klein, L., Klein, T., Ruther, U. \& Kyewski, B. CD4 T cell tolerance to human Creactive protein, an inducible serum protein, is mediated by medullary thymic epithelium. J. Exp. Med. 188, 5-16 (1998).

29 Liston, A., Lesage, S., Wilson, J., Peltonen, L. \& Goodnow, C. C. Aire regulates negative selection of organ-specific T cells. Nature Immunol. 4, 350-354 (2003).

30 Taniguchi, R. T. et al. Detection of an autoreactive T-cell population within the polyclonal repertoire that undergoes distinct autoimmune regulator (Aire)mediated selection. Proc. Natl. Acad. Sci. U S A 109, 7847-7852 (2012).

31 Kurd, N. \& Robey, E. A. T-cell selection in the thymus: a spatial and temporal perspective. Immunol. Rev. 271, 114-126 (2016).

32 Petrie, H. T. \& Zuniga-Pflucker, J. C. Zoned out: functional mapping of stromal signaling microenvironments in the thymus. Annu. Rev. Immunol. 25, 649-679 (2007).

33 Klein, L., Kyewski, B., Allen, P. M. \& Hogquist, K. A. Positive and negative selection of the T cell repertoire: what thymocytes see (and don't see). Nature Rev. Immunol. 14, 377-391 (2014).

34 Ebert, P. J., Ehrlich, L. I. \& Davis, M. M. Low ligand requirement for deletion and lack of synapses in positive selection enforce the gauntlet of thymic T cell maturation. Immunity 29, 734-745 (2008).

35 Peterson, D. A., DiPaolo, R. J., Kanagawa, O. \& Unanue, E. R. Cutting edge: negative selection of immature thymocytes by a few peptide-MHC complexes: differential sensitivity of immature and mature T cells. J. Immunol. 162, 31173120 (1999).

36 Daley, S. R., Hu, D. Y. \& Goodnow, C. C. Helios marks strongly autoreactive CD4+ T cells in two major waves of thymic deletion distinguished by induction of PD-1 or NF-kappaB. J. Exp. Med. 210, 269-285 (2013).

This study reveals the extent, stage, and molecular nature of two distinct waves of clonal deletion in the normal thymus.

37 Stritesky, G. L. et al. Murine thymic selection quantified using a unique method to capture deleted T cells. Proc. Natl. Acad. Sci. U S A 110, 4679-4684 (2013).

This paper uses an elegant method to assess the quantitative impact of clonal deletion at different stages of thymocyte differentiation. 
38 Fontenot, J. D., Dooley, J. L., Farr, A. G. \& Rudensky, A. Y. Developmental regulation of Foxp3 expression during ontogeny. J. Exp. Med. 202, 901-906 (2005).

39 Lee, H. M. \& Hsieh, C. S. Rare development of Foxp3+ thymocytes in the CD4+CD8+ subset. J. Immunol. 183, 2261-2266 (2009).

40 Wirnsberger, G., Mair, F. \& Klein, L. Regulatory T cell differentiation of thymocytes does not require a dedicated antigen-presenting cell but is under $T$ cell-intrinsic developmental control. Proc. Natl. Acad. Sci. U S A 106, 1027810283 (2009).

41 Kishimoto, H. \& Sprent, J. Negative selection in the thymus includes semimature T cells. J. Exp. Med. 185, 263-271 (1997).

42 Le Borgne, M. et al. The impact of negative selection on thymocyte migration in the medulla. Nature Immunol. 10, 823-830 (2009).

43 Ueda, Y. et al. Mst1 regulates integrin-dependent thymocyte trafficking and antigen recognition in the thymus. Nature Commun. 3, 1098 (2012).

44 Dzhagalov, I. L., Chen, K. G., Herzmark, P. \& Robey, E. A. Elimination of selfreactive T cells in the thymus: a timeline for negative selection. PLoS Biol. 11, e1001566 (2013).

45 Sauer, S. et al. T cell receptor signaling controls Foxp3 expression via PI3K, Akt, and mTOR. Proc. Natl. Acad. Sci. U S A 105, 7797-7802 (2008).

This study uses in vitro approaches to suggest that temporal aspects of TCR signalling might be crucial for FOXP3 induction during $T_{\text {reg }}$ cell differentiation.

46 Khailaie, S., Robert, P. A., Toker, A., Huehn, J. \& Meyer-Hermann, M. A signal integration model of thymic selection and natural regulatory $T$ cell commitment. J. Immunol. 193, 5983-5996 (2014).

A bioinformatic study that introduces a TCR signal integration model of thymic selection, describing how thymocyte cell fates might be based upon the TCR stimulation history.

47 Au-Yeung, B. B. et al. Quantitative and temporal requirements revealed for Zap70 catalytic activity during T cell development. Nat Immunol 15, 687-694 (2014).

48 Daniels, M. A. et al. Thymic selection threshold defined by compartmentalization of Ras/MAPK signalling. Nature 444, 724-729 (2006).

49 Mariathasan, S. et al. Duration and strength of extracellular signal-regulated kinase signals are altered during positive versus negative thymocyte selection. J Immunol 167, 4966-4973 (2001).

$50 \mathrm{Wu}, \mathrm{L}$. \& Shortman, K. Heterogeneity of thymic dendritic cells. Seminars in immunology 17, 304-312 (2005).

$51 \mathrm{Hu}, \mathrm{Z}$. et al. CCR7 Modulates the Generation of Thymic Regulatory T Cells by Altering the Composition of the Thymic Dendritic Cell Compartment. Cell Rep. 21, 168-180 (2017).

52 Hadeiba, H. et al. Plasmacytoid dendritic cells transport peripheral antigens to the thymus to promote central tolerance. Immunity 36, 438-450 (2012).

53 Yamano, T. et al. Thymic B Cells Are Licensed to Present Self Antigens for Central T Cell Tolerance Induction. Immunity 42, 1048-1061 (2015).

54 Yamano, T., Steinert, M. \& Klein, L. Thymic B Cells and Central T Cell Tolerance. Front. Immunol. 6, 376 (2015).

55 Hinterberger, M. et al. Autonomous role of medullary thymic epithelial cells in central CD4(+) T cell tolerance. Nature Immunol. 11, 512-519 (2010).

56 Ohnmacht, C. et al. Constitutive ablation of dendritic cells breaks self-tolerance of CD4 T cells and results in spontaneous fatal autoimmunity. J. Exp. Med. 206, 549-559 (2009).

57 van Meerwijk, J. P. et al. Quantitative impact of thymic clonal deletion on the T cell repertoire. J. Exp. Med. 185, 377-383 (1997). 
58 Malek, T. R. The biology of interleukin-2. Annu. Rev. Immunol. 26, 453-479 (2008).

59 Burchill, M. A. et al. Linked T cell receptor and cytokine signaling govern the development of the regulatory T cell repertoire. Immunity 28, 112-121 (2008).

60 Lio, C. W. \& Hsieh, C. S. A two-step process for thymic regulatory T cell development. Immunity 28, 100-111 (2008).

61 Bending, D. et al. A timer for analyzing temporally dynamic changes in transcription during differentiation in vivo. J. Cell. Biol. 217, 2931-2950 (2018).

62 Marshall, D., Sinclair, C., Tung, S. \& Seddon, B. Differential requirement for IL2 and IL-15 during bifurcated development of thymic regulatory T cells. J. Immunol. 193, 5525-5533 (2014).

63 Tai, X. et al. Foxp3 transcription factor is proapoptotic and lethal to developing regulatory $\mathrm{T}$ cells unless counterbalanced by cytokine survival signals. Immunity 38, 1116-1128 (2013).

64 Bayer, A. L., Lee, J. Y., de la Barrera, A., Surh, C. D. \& Malek, T. R. A function for IL-7R for CD4+CD25+Foxp3+ T regulatory cells. J. Immunol. 181, 225-234 (2008).

65 Vang, K. B. et al. IL-2, -7, and -15, but not thymic stromal lymphopoeitin, redundantly govern CD4+Foxp3+ regulatory T cell development. J. Immunol. 181, 3285-3290 (2008).

66 Yao, Z. et al. Nonredundant roles for Stat5a/b in directly regulating Foxp3. Blood 109, 4368-4375 (2007).

67 Bayer, A. L., Yu, A., Adeegbe, D. \& Malek, T. R. Essential role for interleukin2 for CD4(+)CD25(+) T regulatory cell development during the neonatal period. J. Exp. Med. 201, 769-777 (2005).

68 Weist, B. M., Kurd, N., Boussier, J., Chan, S. W. \& Robey, E. A. Thymic regulatory $T$ cell niche size is dictated by limiting IL-2 from antigen-bearing dendritic cells and feedback competition. Nature Immunol. 16, 635-641 (2015).

69 Owen, D. L. et al. Identification of Cellular Sources of IL-2 Needed for Regulatory T Cell Development and Homeostasis. J. Immunol. 200, 3926-3933 (2018).

70 Boursalian, T. E., Golob, J., Soper, D. M., Cooper, C. J. \& Fink, P. J. Continued maturation of thymic emigrants in the periphery. Nature Immunol. 5, 418-425 (2004).

71 Yang-Snyder, J. A. \& Rothenberg, E. V. Spontaneous expression of interleukin2 in vivo in specific tissues of young mice. Dev. Immunol. 5, 223-245 (1998).

72 Wuest, S. C. et al. A role for interleukin-2 trans-presentation in dendritic cellmediated $\mathrm{T}$ cell activation in humans, as revealed by daclizumab therapy. Nature Med. 17, 604-609 (2011).

73 Thiault, N. et al. Peripheral regulatory $T$ lymphocytes recirculating to the thymus suppress the development of their precursors. Nature Immunol. 16, 628-634 (2015).

These results introduce the concept of feedback inhibition of intrathymic $T_{\text {reg }}$ cell differentiation by recirculating $T_{\text {reg }}$ cells from the periphery.

74 Cowan, J. E. et al. Aire controls the recirculation of murine Foxp3(+) regulatory T-cells back to the thymus. Eur. J. Immunol. 48, 844-854 (2018).

75 Moran, A. E. et al. T cell receptor signal strength in Treg and iNKT cell development demonstrated by a novel fluorescent reporter mouse. J. Exp. Med. 208, 1279-1289 (2011).

76 D'Cruz, L. M. \& Klein, L. Development and function of agonist-induced CD25+Foxp3+ regulatory $\mathrm{T}$ cells in the absence of interleukin 2 signaling. Nature Immunol. 6, 1152-1159 (2005).

77 Kishimoto, H. \& Sprent, J. Several different cell surface molecules control negative selection of medullary thymocytes. J. Exp. Med. 190, 65-73 (1999). 
Klein et al.

78 Rubin, R. L. \& Hermanson, T. M. Plasticity in the positive selection of T cells: affinity of the selecting antigen and IL-7 affect $\mathrm{T}$ cell responsiveness. Int. Immuno.l 17, 959-971 (2005).

79 Salomon, B. et al. B7/CD28 costimulation is essential for the homeostasis of the CD4+CD25+ immunoregulatory $\mathrm{T}$ cells that control autoimmune diabetes. Immunity 12, 431-440 (2000).

80 Tai, X., Cowan, M., Feigenbaum, L. \& Singer, A. CD28 costimulation of developing thymocytes induces Foxp3 expression and regulatory $\mathrm{T}$ cell differentiation independently of interleukin 2. Nature Immunol. 6, 152-162 (2005).

81 Lio, C. W., Dodson, L. F., Deppong, C. M., Hsieh, C. S. \& Green, J. M. CD28 facilitates the generation of Foxp3(-) cytokine responsive regulatory $\mathrm{T}$ cell precursors. J. Immunol. 184, 6007-6013 (2010).

82 Vang, K. B. et al. Cutting edge: CD28 and c-Rel-dependent pathways initiate regulatory T cell development. J. Immunol. 184, 4074-4077 (2010).

83 Hinterberger, M., Wirnsberger, G. \& Klein, L. B7/CD28 in central tolerance: costimulation promotes maturation of regulatory $\mathrm{T}$ cell precursors and prevents their clonal deletion. Front. Immunol. 2, 30 (2011).

84 Murray, M. E. et al. CD28-mediated pro-survival signaling induces chemotherapeutic resistance in multiple myeloma. Blood 123, 3770-3779 (2014).

85 Bouillet, $\mathrm{P}$. et al. BH3-only Bcl-2 family member Bim is required for apoptosis of autoreactive thymocytes. Nature 415, 922-926 (2002).

86 Ouyang, W., Beckett, O., Ma, Q. \& Li, M. O. Transforming growth factor-beta signaling curbs thymic negative selection promoting regulatory $\mathrm{T}$ cell development. Immunity 32, 642-653 (2010).

87 Punt, J. A., Havran, W., Abe, R., Sarin, A. \& Singer, A. T cell receptor (TCR)induced death of immature CD4+CD8+ thymocytes by two distinct mechanisms differing in their requirement for CD28 costimulation: implications for negative selection in the thymus. J. Exp. Med. 186, 1911-1922 (1997).

88 Dautigny, N., Le Campion, A. \& Lucas, B. Timing and casting for actors of thymic negative selection. J. Immunol. 162, 1294-1302 (1999).

89 Jones, L. A., Izon, D. J., Nieland, J. D., Linsley, P. S. \& Kruisbeek, A. M. CD28B7 interactions are not required for intrathymic clonal deletion. Int. Immunol. 5, 503-512 (1993).

90 Page, D. M., Kane, L. P., Allison, J. P. \& Hedrick, S. M. Two signals are required for negative selection of CD4+CD8+ thymocytes. J. Immunol. 151, 1868-1880 (1993).

91 Tan, R., Teh, S. J., Ledbetter, J. A., Linsley, P. S. \& Teh, H. S. B7 costimulates proliferation of CD4-8+ T lymphocytes but is not required for the deletion of immature CD4+8+ thymocytes. J. Immunol. 149, 3217-3224 (1992).

92 Walunas, T. L., Sperling, A. I., Khattri, R., Thompson, C. B. \& Bluestone, J. A. CD28 expression is not essential for positive and negative selection of thymocytes or peripheral T cell tolerance. J. Immunol. 156, 1006-1013 (1996).

93 Pobezinsky, L. A. et al. Clonal deletion and the fate of autoreactive thymocytes that survive negative selection. Nature Immunol. 13, 569-578 (2012).

This study reconciles conflicting data on the role of CD28 in clonal deletion.

94 Collette, Y., Benziane, A., Razanajaona, D. \& Olive, D. Distinct regulation of Tcell death by CD28 depending on both its aggregation and T-cell receptor triggering: a role for Fas-FasL. Blood 92, 1350-1363 (1998).

95 Li, M. O. \& Flavell, R. A. TGF-beta: a master of all T cell trades. Cell 134, 392404 (2008).

96 Chen, W. et al. Conversion of peripheral CD4+CD25- naive $T$ cells to CD4+CD25+ regulatory T cells by TGF-beta induction of transcription factor Foxp3. J. Exp. Med. 198, 1875-1886 (2003). 
Klein et al.

97 Kretschmer, K. et al. Inducing and expanding regulatory T cell populations by foreign antigen. Nature Immunol. 6, 1219-1227 (2005).

98 Zheng, Y. et al. Role of conserved non-coding DNA elements in the Foxp3 gene in regulatory T-cell fate. Nature 463, 808-812 (2010).

$99 \mathrm{Li}, \mathrm{M}$. O., Sanjabi, S. \& Flavell, R. A. Transforming growth factor-beta controls development, homeostasis, and tolerance of $\mathrm{T}$ cells by regulatory $\mathrm{T}$ celldependent and -independent mechanisms. Immunity 25, 455-471 (2006).

100 Marie, J. C., Letterio, J. J., Gavin, M. \& Rudensky, A. Y. TGF-beta1 maintains suppressor function and Foxp3 expression in CD4+CD25+ regulatory $T$ cells. J. Exp. Med. 201, 1061-1067 (2005).

101 Liu, Y. et al. A critical function for TGF-beta signaling in the development of natural CD4+CD25+Foxp3+ regulatory T cells. Nature Immunol. 9, 632-640 (2008).

102 Chen, W. et al. Requirement for transforming growth factor beta1 in controlling T cell apoptosis. J. Exp. Med. 194, 439-453 (2001).

103 Schlenner, S. M., Weigmann, B., Ruan, Q., Chen, Y. \& von Boehmer, H. Smad3 binding to the foxp3 enhancer is dispensable for the development of regulatory T cells with the exception of the gut. J. Exp. Med. 209, 1529-1535 (2012).

104 Konkel, J. E., Jin, W., Abbatiello, B., Grainger, J. R. \& Chen, W. Thymocyte apoptosis drives the intrathymic generation of regulatory T cells. Proc. Natl. Acad. Sci. U S A 111, E465-473 (2014).

105 Chen, W. \& Konkel, J. E. Development of thymic Foxp3(+) regulatory T cells: TGF-beta matters. Eur. J. Immunol. 45, 958-965 (2015).

106 Anderson, M. S. et al. Projection of an immunological self shadow within the thymus by the aire protein. Science 298, 1395-1401 (2002).

107 Derbinski, J., Schulte, A., Kyewski, B. \& Klein, L. Promiscuous gene expression in medullary thymic epithelial cells mirrors the peripheral self. Nature Immunol. 2, 1032-1039 (2001).

108 Mathis, D. \& Benoist, C. A decade of AIRE. Nature Rev. Immunol. 7, 645-650 (2007).

109 Peterson, P., Org, T. \& Rebane, A. Transcriptional regulation by AIRE: molecular mechanisms of central tolerance. Nature Rev. Immunol. 8, 948-957 (2008).

110 Derbinski, J. et al. Promiscuous gene expression in thymic epithelial cells is regulated at multiple levels. J. Exp. Med. 202, 33-45 (2005).

111 Takaba, H. et al. Fezf2 Orchestrates a Thymic Program of Self-Antigen Expression for Immune Tolerance. Cell 163, 975-987 (2015).

112 Sansom, S. N. et al. Population and single-cell genomics reveal the Aire dependency, relief from Polycomb silencing, and distribution of self-antigen expression in thymic epithelia. Genome. Res. 24, 1918-1931 (2014).

113 Smith, K. M., Olson, D. C., Hirose, R. \& Hanahan, D. Pancreatic gene expression in rare cells of thymic medulla: evidence for functional contribution to T cell tolerance. Int. Immunol. 9, 1355-1365 (1997).

114 Brennecke, P. et al. Single-cell transcriptome analysis reveals coordinated ectopic gene-expression patterns in medullary thymic epithelial cells. Nature Immunol. 16, 933-941 (2015).

115 Meredith, M., Zemmour, D., Mathis, D. \& Benoist, C. Aire controls gene expression in the thymic epithelium with ordered stochasticity. Nature Immunol. 16, 942-949 (2015).

116 Nedjic, J., Aichinger, M., Mizushima, N. \& Klein, L. Macroautophagy, endogenous $\mathrm{MHC}$ II loading and T cell selection: the benefits of breaking the rules. Curr. Opin. Immunol. 21, 92-97 (2009).

117 Bonasio, R. et al. Clonal deletion of thymocytes by circulating dendritic cells homing to the thymus. Nature Immunol. 7, 1092-1100 (2006). 
Klein et al.

118 Perry, J. S. A. et al. CD36 Mediates Cell-Surface Antigens to Promote Thymic Development of the Regulatory T Cell Receptor Repertoire and Allo-tolerance. Immunity 48, 923-936 e924 (2018).

119 Lee, H. M., Bautista, J. L., Scott-Browne, J., Mohan, J. F. \& Hsieh, C. S. A broad range of self-reactivity drives thymic regulatory $\mathrm{T}$ cell selection to limit responses to self. Immunity 37, 475-486 (2012).

120 Simons, D. M. et al. How specificity for self-peptides shapes the development and function of regulatory T cells. J. Leukoc. Biol. 88, 1099-1107 (2010).

121 Atibalentja, D. F., Murphy, K. M. \& Unanue, E. R. Functional redundancy between thymic CD8alpha+ and Sirpalpha+ conventional dendritic cells in presentation of blood-derived lysozyme by MHC class II proteins. J. Immunol. 186, 1421-1431 (2011).

122 Feuerer, M. et al. Enhanced thymic selection of FoxP3+ regulatory $T$ cells in the NOD mouse model of autoimmune diabetes. Proc. Natl. Acad. Sci. U S A 104, 18181-18186 (2007).

123 Relland, L. M. et al. Affinity-based selection of regulatory T cells occurs independent of agonist-mediated induction of Foxp3 expression. J. Immunol. 182, 1341-1350 (2009). 

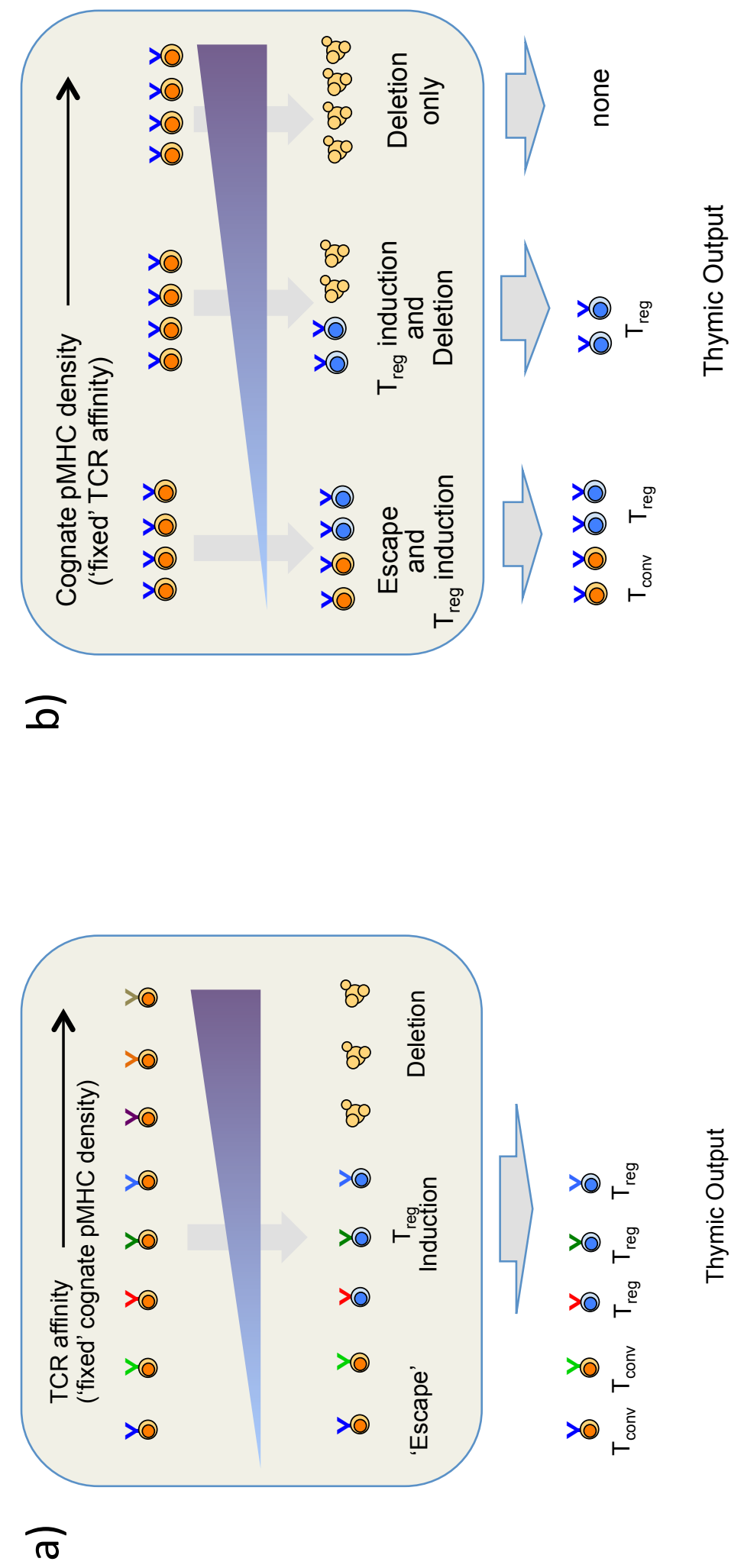


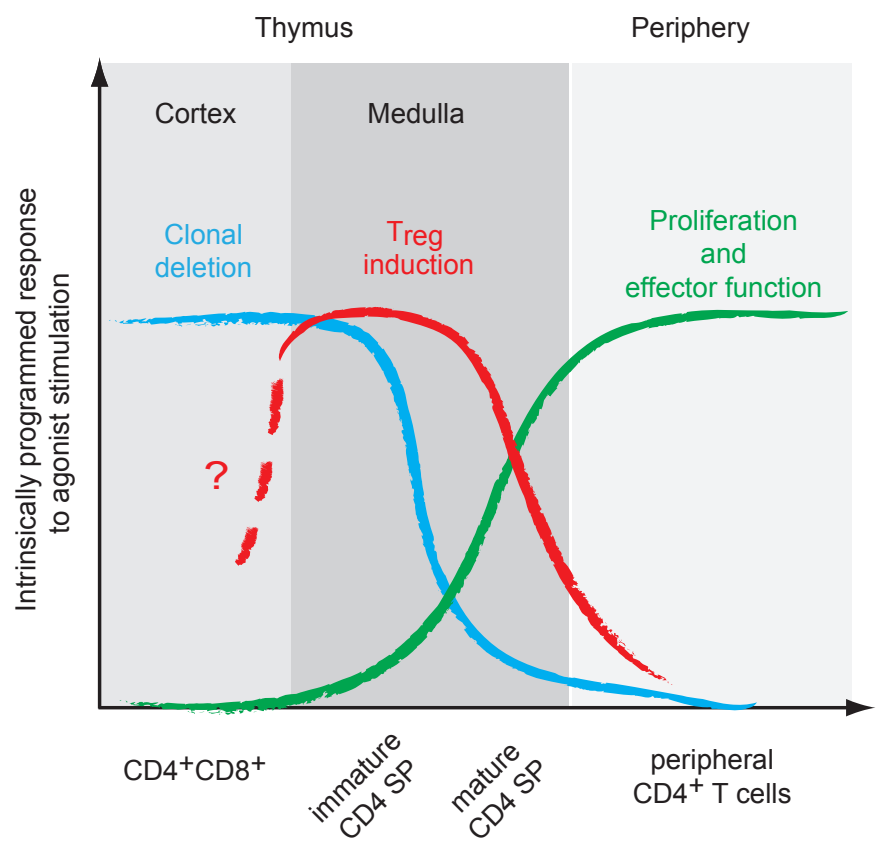

Figure 2 

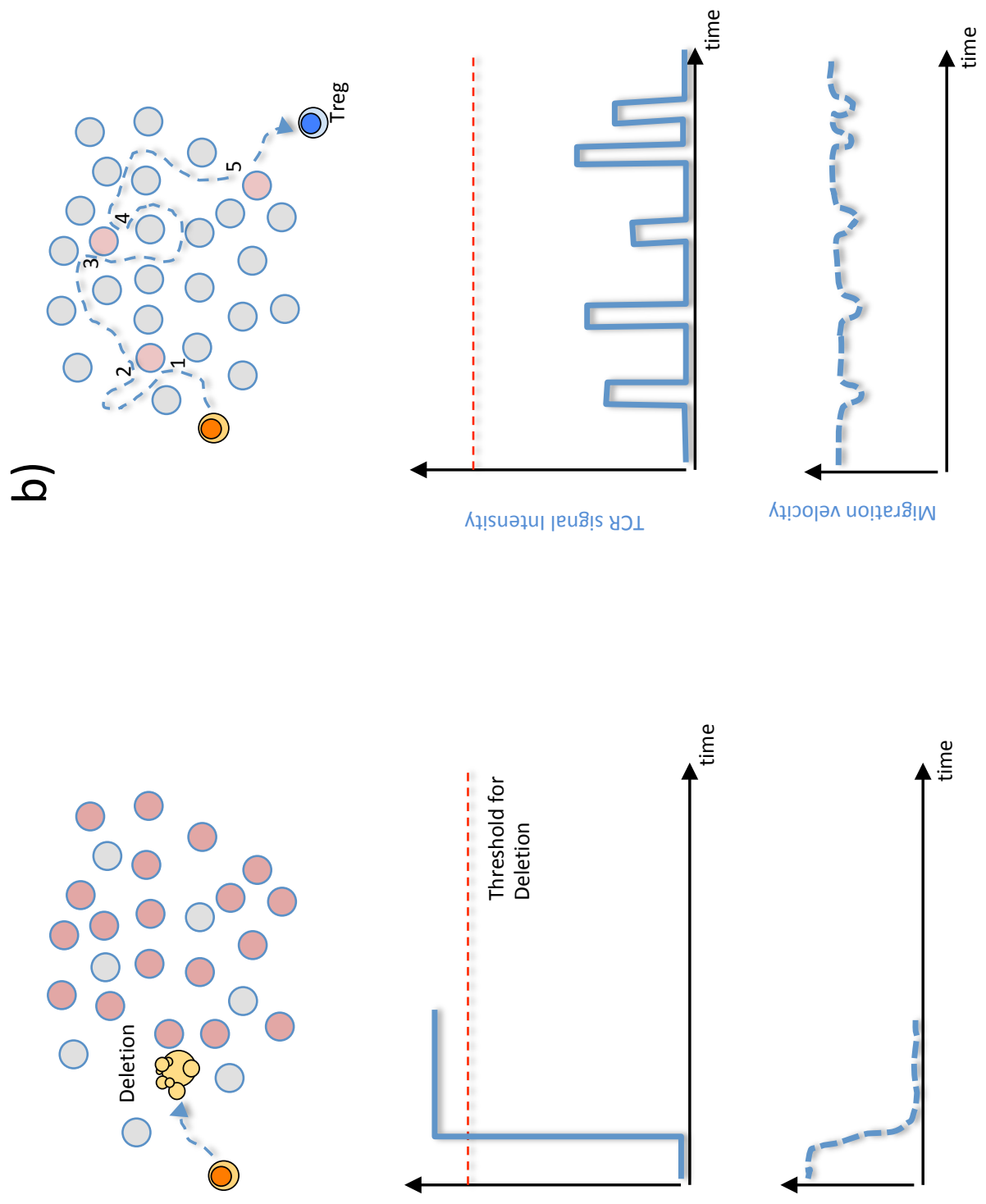

$\pi$
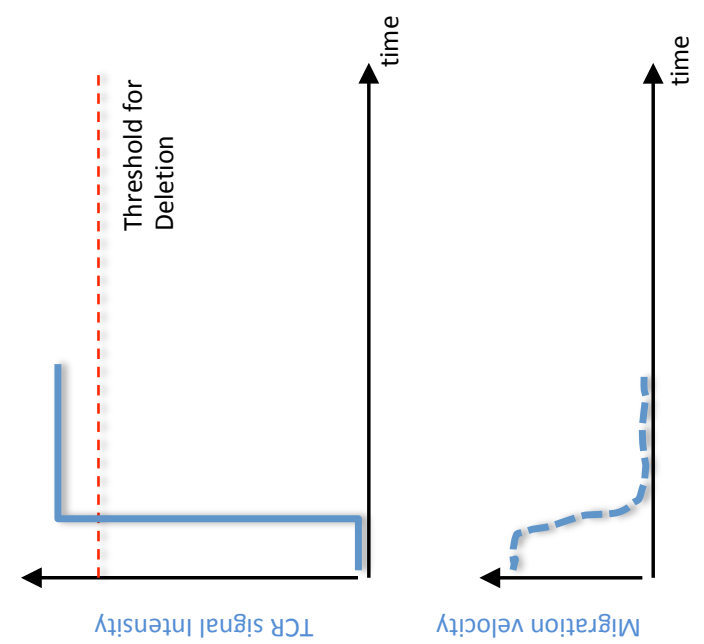

$m$
$\frac{0}{3}$
$\frac{0}{4}$ 


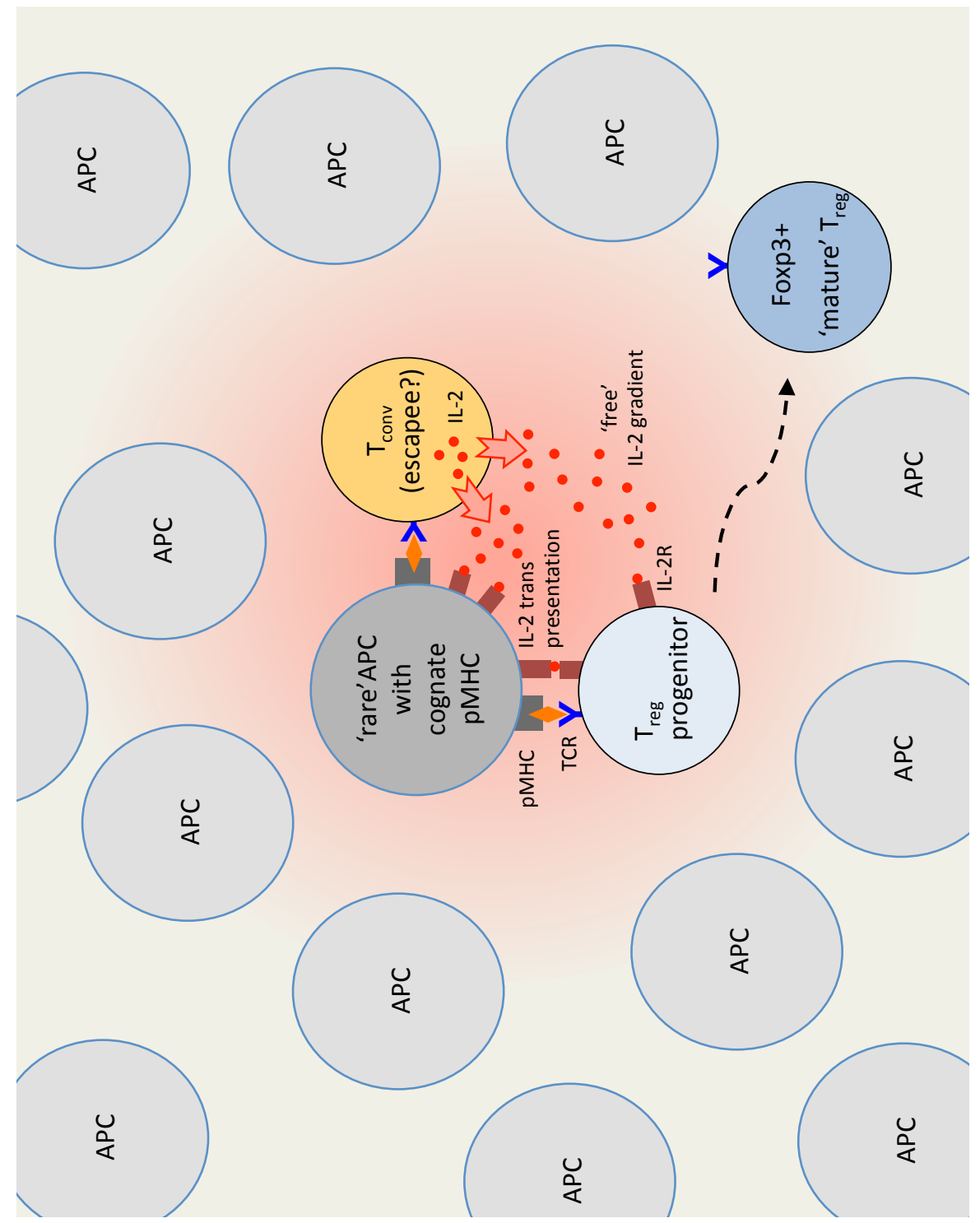




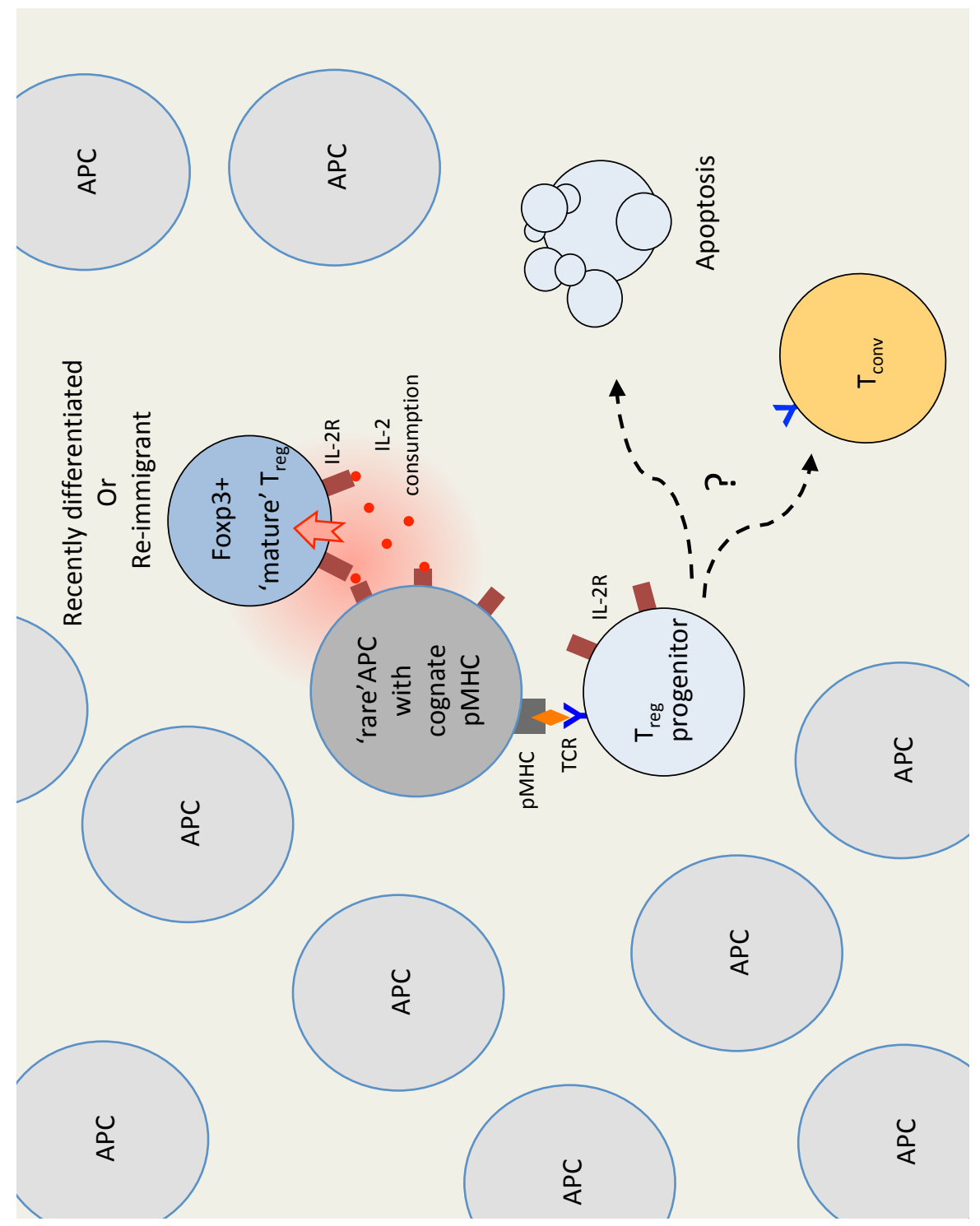



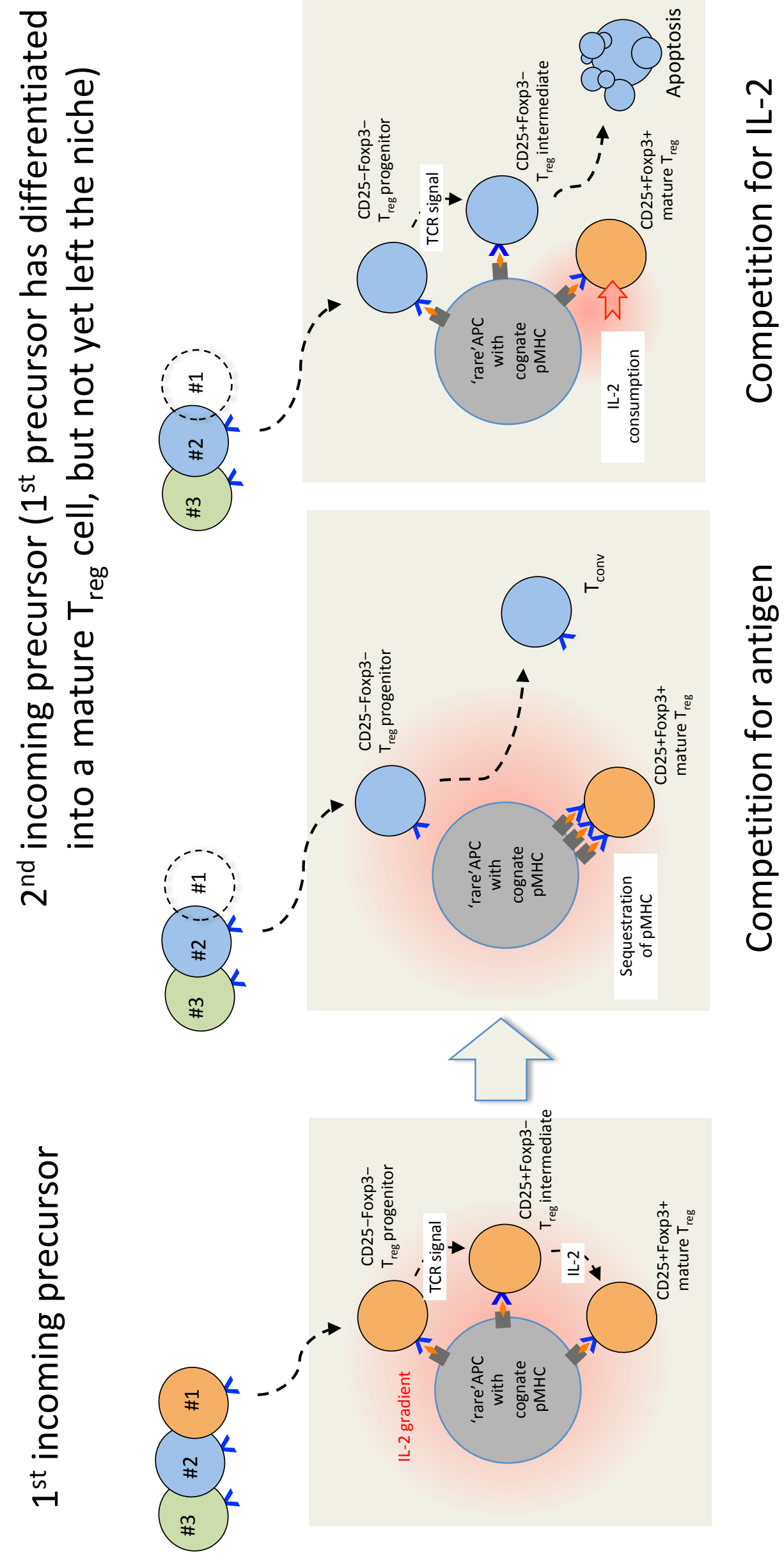